\title{
'Trust in Recordkeeping'
}

by

\section{Jean Hitchcock}

\author{
Submitted to the School of Information Management, \\ Victoria University of Wellington \\ in partial fulfilment of the requirements for the degree of \\ Master of Information Studies
}

June 2014 


\section{ABSTRACT}

\section{Research Problem}

Compliance in recordkeeping is essential,_especially in public service organisations that are required to comply with the Public Records Act (PRA) of New Zealand, which lays down strict guidelines for recordkeeping to aid in transparency in government. Records must be comprehensive and complete, as well as authentic and reliable. People are less likely to use a system if they do not trust it. There are various factors influencing compliance; this research examines trust in the recordkeeping system itself, and the factors that enhance or diminish trust.

\section{Methodology}

This quantitative research was conducted using an online questionnaire in March of 2014. It was disseminated via New Zealand's listserv for the recordkeeping community and it was sent to records managers because they understand the PRA, and have a holistic view of recordkeeping; and also would have an overview of staff compliance and attitudes. Text questions were included at the end, giving people an opportunity to explain or expand on their answers.

Findings

Results were varied, reflecting the diversity of organisations affected by the PRA as well as diversity in standards of recordkeeping and compliance. Some results were clear, with all respondents seeing the benefit of support from management. Different problems were experienced in different organisations, and strategies to enhance trust and consequences of mistrust were listed.

Implications

With increased knowledge about the factors affecting trust in recordkeeping systems, as well potential solutions, records managers can have a better chance of running or implementing a successful system. People factors play a large role in the success of a system, and record managers need to find ways to achieve user buy-in. Different solutions work in different organisations. Further research into the other factors affecting compliance in recordkeeping systems is indicated. 


\section{Table of contents}

1 Introduction 1

1.1Rationale and objectives 2

1.2Research Question 3

1.3Theoretical Framework 4

1.4Definition of Terms 5

2. Review of the Literature 6

2.1 Organisational culture 10

2.2 The New Zealand Context 12

3. Research Design 13

3.1 Ethical Considerations 13

3.2 Research Limitations $\quad 15$

3.3 Research assumptions $\quad 15$

3.4 Data Analysis 16

4. Findings 16

4.1 Multiple choice questions and graphs $\quad 16$

4.2 Text questions 33

5. Discussion 34

5.1 Further research opportunities $\quad 42$

6. Conclusion 44

7. Acknowledgements 45

8. Bibliography 46

Figures and Tables $\quad 54$

8. Appendices 55

Appendix A: Copy of Self-completion Questionnaire

Appendix B: Letter that accompanied emailed questionnaire 


\section{Introduction}

Transparency of government is seen as a cornerstone of democracy (Cox, 2006; Donnelly, 2008). For this transparency to occur, transactions undertaken by government on behalf of the people must be open to scrutiny (Shepherd, Stevenson \& Flinn, 2009), and records are the evidence of these transactions (Reed, 2005; Kennedy \& Schauder, 1998). Internationally several countries, including Canada, Australia and the UK have introduced freedom of information legislation, and to enable compliance with the law records must be adequately managed (Shepherd et al., 2009). New Zealand has the Official Information Act and the Public Records Act (PRA) of 2005, which: "makes all central and local government organisations responsible for creating and maintaining full and accurate records of their activities" (Archives New Zealand, 2006).

Archives New Zealand has the mandate to administer the PRA and they (Archives New Zealand, 2014b) state, "The PRA sets the framework for creating and managing information in government. Its purpose is to promote local government accountability through reliable recordkeeping, enhance public confidence in the integrity of local government records and protect New Zealand's documentary heritage." The international standard, ISO 15489, lays down the framework for best practice (Shepherd et al., 2009; Archives New Zealand, 2014c).

With changes in technology recordkeeping is increasingly becoming responsibility of all staff and no longer solely the province of the records manager (Cox, 2006; Downing, 2006). For people to use a system adequately, they need to trust it to perform as required (Johnston \& Bowen, 2005; Oliver \&Foscarini, 2014). Trust in recordkeeping is needed in multiple ways; records need to be authentic and reliable (Johnston \& Bowen, 2005) as well as comprehensive and complete (Archives New Zealand, 2006). This research examines trust in the recordkeeping systems themselves.

Trust is a difficult concept to define (McNeish \& Mann, 2010), though trust is based on interactions and expectations, and trust shows in people's behavior (Huotari \& livonen, 2004). Technical systems are prone to the consequences of users' loss of trust (Nothdurft, Heinroth, \& Minker, 2013). 
This research examines the attitudes and practices of staff in the public service with recordkeeping responsibility in New Zealand. The research was conducted from the point of view of the records manager; this approach was chosen because these are the people who understand the PRA, they have a holistic view of recordkeeping, (McLeod, Childs, \&Hardiman, 2011) as well as the experience to see what works and what does not. The research takes a current and cross-sectional view of how systems are viewed and used; and identifies strategies to foster trust that have been implemented and found to be effective.

\subsection{Rationale and objectives of the study}

It is evident from the literature that people factors play a large role in recordkeeping (Oliver \&Foscarini, 2014; McLeod, Childs \& Hardiman, 2011). In aiming for transparency in government and the principles of the PRA all factors need to be considered to ensure recordkeeping that is full and accurate enough to support government accountability (Archives New Zealand, 2006). The workplace has changed dramatically in the last few decades and records professionals need to pay attention to the changing technological infrastructure of the organisations they work in (Cox, 2006). To encourage employees to use systems effectively, we need to examine whether employees trust the records management systems they are expected to use (Oliver \& Foscarini, 2014). Huotari and livonen (2004) believe that the management of people is as crucial as the management of information when managing knowledge as a resource. Johnston and Bowen (2005) state that the notion of trust is important, they feel that technically an EDRMS can be trusted to ensure that records are authentic and reliable, but that a key element to success is user acceptance.

I have personally seen senior staff in large organisations hiding files in cupboards to avoid putting them in the mobile shelving, where they could be misfiled or, even worse, sent to off-site storage. Similarly, I have seen people panic over lost digital files that were not put into the EDRMS (Electronic Documents and Records Management System), but rather left on the computer desktop. With a computer upgrade all these files were lost.

Several authors (Gunnlaugsdottir, 2009; Oliver \& Foscarini, 2014) have witnessed organisations where systems were used incorrectly or bypassed due to mistrust. This study conducts research into the current state of recordkeeping in New Zealand in organisations affected by the PRA, to see how we relate to international findings and as an attempt to 
identify local barriers to good recordkeeping, as well as strategies that help to build trust.

The findings will potentially be useful to organisations implementing an EDRMS or a change or upgrade in systems; and to records managers who are struggling to encourage staff to comply with recordkeeping procedures. This research aims to highlight the problems records managers are currently experiencing; findings should pinpoint common problems and potential solutions. This is vital for the public sector needing to comply with the requirements of the Public Records Act. Every system needs to be both efficient and effective. It is more cost-effective for an organisation to achieve staff compliance from the start of a project. It could be useful for recordkeepers to be able to demonstrate to their managers the benefits of better staff training and compliance, and the strategies that enhance trust in their recordkeeping system.

\subsection{Research questions}

\section{Main Question}

To what extent do records managers perceive that lack of trust impacts on employee use of recordkeeping systems?

\section{Secondary Question}

What strategies do records managers implement to encourage employee use of recordkeeping systems? 


\subsection{Theoretical Framework}

This research is based on the recordkeeping continuum theory; the continuum model was developed by Frank Upward and his colleagues at Monash University in Australia It focuses on the management of records as a continuous process (Kennedy \& Schauder, 1998). Upward $(2000$, p.127) states that the continuum theory provides: "a worldview that can help harness the development of knowledge in archives and records management globally". However he notes that every worldview has its limitations.

The continuum model focuses on managing records from the perspective of the activities that they document; Kennedy and Schauder (1998, p.10) summarize this by saying it manages:"what needs to be captured to provide evidence of an activity, what systems and rules are needed to ensure those records are captured and maintained, how long the records should be kept to meet business and other requirements, how they should be stored, and who should have access to them". Upward (2000, p. 116) elaborates that it presents a view of recordkeeping: "at the point of creation, within groups, at organisational levels, and at inter-organisational levels." He states that it provides a layered and interconnected model for the ongoing management of systems.

Figure 1: The Recordkeeping Continuum (Upward, 2000, p123)

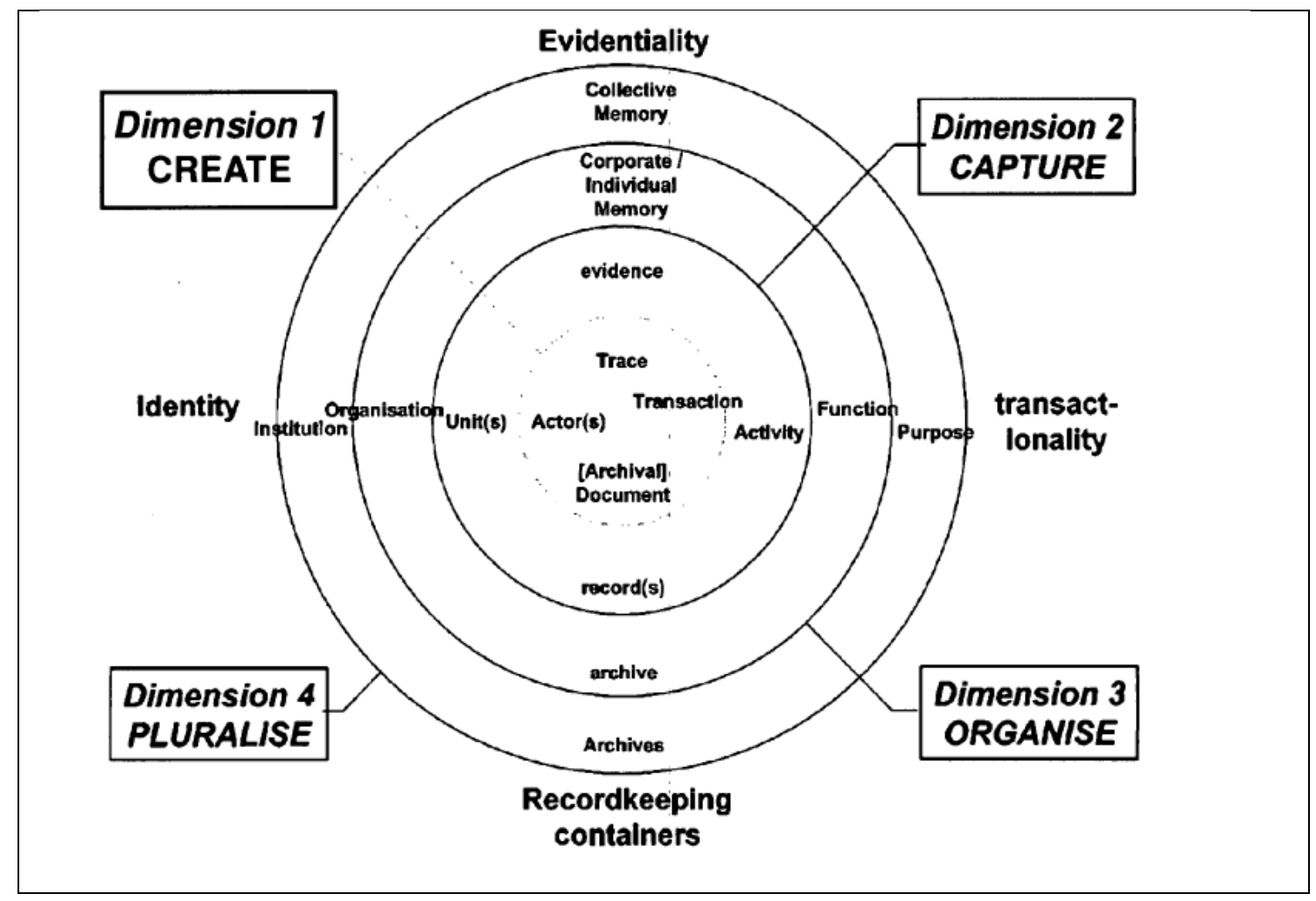


As seen in Figure 1 the records continuum model uses four dimensions and four axes as a tool to make sense of the complex recordkeeping task. The four dimensions are create, capture, organize and pluralize; and the axes are recordkeeping, identity, evidentiality and transactionality. This research is concerned with all four dimensions but particularly the first one; create. Upward (2000, p.122) explains that create is the stage where individuals are creating information to document their business activities, the capture dimension occurs when documents that have been created are assigned controls, like metadata and file names; organize allows the processes to ensure that the records can be shared across a range of participants and pluralize is concerned with the spread of information outside of the organisation. Using the model makes recordkeeping proactive (Kennedy and Schauder, 1998) rather than reactive, where records are managed after they have been created.

\subsection{Definition of terms}

\section{$\underline{\text { Records }}$}

The internationally accepted ISO 15489 definition of a record is: "Information created, received, and maintained as evidence and information by an organization or person, in pursuance of legal obligations or in transaction of business" (Archives New Zealand, 2006). Records have multiple purposes (McKemmish, 2005) and can be trusted when preserved in systems that maintain their integrity, and can then be used as evidence. According to Cox (2006) the evidential value of a record can only exist if the content, structure, and context are preserved. The context is the link between different records that belong together and also to the process where the record was created.

\section{Recordkeeping systems}

Recordkeeping systems are systems designed to capture records as evidence of business activities, to manage those records, and to make them available when required. (Kennedy \& Schauder, 1998). Record management systems are referred to in different ways by authors in different countries. Systems can manage paper records or electronic records, or both. They can be ERMS (electronic records management systems), or EDMS (electronic document and records management systems) or EDRMS (electronic documents and records management systems) (Johnston \& Bowen, 2005). While there are distinctions between these, this research is concerned with the social rather than the technical aspects of records 
management, and will use EDRMS for all records (including paper records) that are managed electronically. The questionnaire was written for both paper records and digital, and hybrid systems.

\section{Records managers}

Foscarini (2010) sees the role of the records manager as mediators between system developers, standards and system users. According to Barsoum (2006) comprehensive records management has taken on an increased importance, with companies under increased regulatory scrutiny. Traditionally, records management has been seen as the responsibility of records staff, with EDRMS implementation this responsibility is broadened (Nguyen, Swatman, Fraunholz, \& Salzman, 2009); and other staff also have recordkeeping responsibilities.

\section{Review of the Literature}

Trust plays a variety of roles in recordkeeping. Trust, as Sundqvist (2011) tells us, is a fluid concept; with the general notion being an assumption that your expectations will be fulfilled. She adds that trust is necessary for us to cope with the complexities of daily life. The sociologist, Nooteboom (2010, p.4), believes that trust is not all-or-nothing; that there are degrees of trust, and that these degrees of trust are difficult or impossible to measure. He explains that it is natural for people to have two frames of mind; because humans have an instinct for survival and the guarding of our resources, as well as an inclination to be a loyal member of a community. The frame of mind depends on the individual, their character, experience and circumstances.

The foundations of human society are built on trust (MacDonald, 2012), and we could not conduct our modern lives without trust; however, as stated by McNeish and Mann (2010), trust is a difficult concept to define. One definition of trust from the Oxford Dictionary (Oxford University Press, 2014) is the "firm belief in the reliability, truth, or ability of someone or something." Huotari and livonen $(2003$, p. 8) summarize their findings about trust by stating that

- trust is based on expectations and interaction

- trust manifests in people's behavioral patterns 
- trust makes a difference

They go on to explain that because trust is based on people's expectations it is necessary to understand these expectations to build a trusting relationship.

Records are instruments of trust as well as objects of trust in themselves (Sundqvist, 2011); and we need to be able to trust records to be authoritative enough to support or deny actions (McKemmish, 2005). To ensure effective recordkeeping, Oliver and Foscarini (2014, p.153) tell us: "We need to not only make sure that our systems are trustworthy, but also make sure that our users too share that trust." The hallmark of recordkeeping is the documentation of business activities (Reed 2009), and a record is inherently transactional. Businesses and corporations need recordkeeping systems, both to function and to discharge their legal obligations. Freedom of information is important to democracy (Cox, 2006; Donnelly,2008) and citizens have a right to expect that the data will be accurate; poorly kept records result in inaccurate and incomplete data, with potentially serious consequences (Thurston, 2012).

Recordkeeping must also comply with certain standards; according to Carlisle (2008), the standards provide a benchmark of expectations and outcomes that can be used to gain consistency. At the international level, the predominant organisation developing standards is the International Organization for Standardization, responsible for the international recordkeeping standard ISO 15489. This provides a framework and guidelines for good records management and in New Zealand is endorsed by Archives New Zealand (2014c), who assist government in complying with the standard. To implement this standard successfully it is essential (Oliver, 2011) that all staff participate.

This international standard defines eleven key elements that are required for a comprehensive records management program, and they ensure that the organisation's records are "appropriately captured and identified, protected, and eventually destroyed in accordance with predefined rules "(Carlisle 2008, p. 57). One clause of the ISO 15489 states that all organisations should have a formally agreed policy for recordkeeping that is "adopted and endorsed at the highest decision-making level and promulgated throughout the organization" (Shepherd \& Yeo, 2003).

Several international governments accept the concept of access to information or freedom of information, and have introduced appropriate legislation to ensure this (Shepherd, Stevenson, \& Flinn, 2009). In New Zealand we have the Official information Act 
(Donnelly, 2008) and the Public Records Act (PRA) of 2005; and Archives New Zealand (2013b) states, "The PRA sets the framework for creating and managing information in government. Its purpose is to promote local government accountability through reliable recordkeeping, enhance public confidence in the integrity of local government records and protect New Zealand's documentary heritage." Donnelly (2008) states that good recordkeeping practice is vital to maintain the quality and integrity of public records, and that good governance and quality recordkeeping are linked; also poor recordkeeping undermines the checks and balances on public agencies.

In a study of human computer interaction ( $\mathrm{HCl})$, ( Nothduft et al., 2013) it was found that maintaining the trustworthiness of the systems was crucial to keep the user willing to interact with the system, and that explanations could help to remedy a loss of trust. According to McLeod and Childs (2013) there is no silver bullet for electronic records management, and the full impact of the system chosen will only become apparent over time; sometimes with unanticipated or undesirable consequences. Support for end-users is essential (Di Biagio and Ibiricu, 2008) to overcome uncertainty, and training and communication are tools that can help overcome users' resistance.

As stated by Barsoum (2006,) records management is an on-going process and it needs monitoring; standards, software hardware and other technologies keep changing and continual support and training is critical. Cox (2006) adds that in the information age, the records management discipline is experiencing rapid changes. McDonald (2005, p.5) identifies the main cause of user resistance as a failure to identify and define work processes. He also identifies the lack of understanding of the benefits of a system, lack of user friendliness, lack of integration with other technologies and inadequate approaches to classification and retrieval, as contributing to resistance.

Some users see EDRMS as a threat (Johnston \& Bowen, 2005) so it is important that the system does not change work-flow and can be used by people with different levels of computer skill. Motivated employees (Wilson, 2005) are essential to change and adapt with today's fast-paced business environment, and keeping employees motivated is complex. $\mathrm{Di}$ Biagio and Ibiricu (2008) identify management backing as essential in implementing a system and getting end user support. However, they feel that a monitoring framework should be implemented to ensure compliance with the new systems and to enable corrective measures. 
A key element in the implementation and use of an EDRMS is user acceptance (Johnston \& Bowen, 2005), and people need to be shown how they and their organisation will benefit from the system. Looking back over two decades of managing electronic records Mcleod and Childs (2013) found that successful records management is still a problem for many organisations. They used a Cynefin framework to test data from an empirical research project that investigated strategies for improving electronic records management. The data had been gathered from participants around the world, in research conducted over a period of years. They concluded that the people issues around electronic data management can be managed, but that understanding the nature of the issues is vital to selecting the right approaches to tackling them.

The case study of the European Central bank (Di Biago \&lbiricu, 2008) aimed to analyse the experience of implementing an EDRMS, and to highlight experiences that could be potential sources of success or failure for other implementations. They found that EDRMS is not a solution to records management on its own, and that if records management discipline was not already present, bad habits return. They also identified detailed procedures as a tool that enabled users to exploit the potential of a new system. Management backing and communication and training were stressed as ways to instigate a high records management standard.

In their review of both published and unpublished case studies, Johnston and Bowen (2005) aimed to identify the benefits achieved by implementing an EDRMS. Their conclusion is that while EDRMs provide benefits, these are not assured. They depend on both a good implementation process and attention being paid to the human aspects of the EDRMS. A study by Loadman (2001) focuses on relationships within the organisation. She felt that records management needs a defined place within an organisation to perform effectively.

Gunnlaugsdottir (2009) interviewed employees across eight organisations in Iceland to discover how they felt about using EDRMS. She used both open-ended interviews and participant observation. Four different EDRMS were being used, and all four met the requirements for ISO 15489, and for Icelandic law. She identified three main elements contributing to the successful implementation of EDRMS; these were support by top management, participation of records manager in adapting the EDRMS to the needs of the organisation, and the provision of adequate training. Manager involvement was also crucial in the implementation of an EDRMS at the European Central Bank (Di Biago \& Ibiricu, 2008). 
The best results were found where managers had actively promoted the system, by being involved in the implementation work; ongoing support was also found to be important.

In a 3-year project researchers at the University of Northumbria conducted global research into electronic records management issues. They found that "the people, process and systems/technology aspects of ERM are inextricably linked" and that "people issues are predominant, fundamental and challenging" (McLeod et al., 2011, p.5). According to Johnston and Bowen, (2005) a recordkeeping system in is more than just the software, it is a complete system that involves people carrying out their jobs. Their finding was that electronic records management systems can be trusted to both do the technical work (with a variety of types of record, from paper to video), and to ensure that records are authentic and reliable. Training was also seen as a way to allay the fears of staff.

Examining user expectations, Joseph, Debowski and Goldschmidt (2012, p.62) concluded that: "...knowledge workers want business solutions that are aligned to how they work, so that their daily work experience is made easy, saves them time and effort and importantly does not frustrate their information seeking and work effectiveness." They state that the traditional records management approach has not achieved the widespread engagement by users that was intended; and suggest that recordkeeping tasks, like metadata and classification, need to be simplified and automated as much as possible. McDonald $(2005$, p.9) believes that little progress will be made as long as staff view records as "the residue of their actions, or some administrative overhead".

\section{$\underline{2.1 \text { Organisational Culture }}$}

Sun (2008) tells us that culture within organisations plays a critical role in an organisation's everyday operations and that every organisation has its own unique culture. Hofstede, an influential social psychologist conducted pioneering research into cultures and organisations, has described organisational culture as (Hofstede, 2011, p.3) "the collective programming of the mind that distinguishes the members of one organisation from others". He also sees technological modernization as an important factor in culture change. As stated by Bearman (1995) we must take actions to create "a corporate culture in which employees take the documentation of their activities seriously."

Oliver (2011) has found that careful analysis of organisations will help ensure that cultural values and attitudes to information assist good practice in records management. Too many planned organisational change initiatives fail and Judge and Thomas (2009) 
identify a need to study the organisational capacity for change, and they conclude that managers need to ensure that organisations are better prepared for change and more flexible. Systems are continually changing and evolving, with software and hardware upgrades (Cox, 2006) and electronic management systems will face continued reinventions (McLeod \& Childs, 2013).

Organisational cultures take a long time to form and can be very resistant to change; helping people overcome their limitations and to become more successful at work is at the very heart of effective management (Kegan \& Lahey, 2001). Organisational expectations have shifted (Joseph, Debowski \& Goldschmidt, 2012, p.63) and recordkeeping responsibilities have moved "from records managers to individual knowledge workers who are generally unskilled in records management practices".

In their study Chawla and Kelloway (2004) focused on the direct effects of trust and faith in management, and the role they play in overcoming resistance to change. They suggest that employee-focused change management can help organisations during a large-scale change.

Reed (2009) notes that recordkeeping professionals can be resistant to change, focusing on the system rather than the changing needs of the information environment. Studies in libraries have produced similar results. In a Canadian study Williamson (2008) found that the greatest challenge to transforming library services lay in transforming the knowledge, skills and abilities of library staff, and to overcome the traditionally conservative approach to librarianship. He points out that the greatest threat to the profession is the librarian's own attitude towards change. Looking at a case study in the UK (Farley, BroadyPreston, \& Hayward, 1998) researchers found that the first step towards management of change in libraries is the acknowledgement and understanding of the human element in organisations. The four areas found to be crucial for successful change management were communication and information-sharing, staff involvement and participation, training and development, and job design. Unless attention was paid to these, staff could mount considerable resistance, and their motivation, commitment and job satisfaction could be damaged. During their global research McLeod et al. (2011) found that recordkeepers admitted that they could be part of the problem as well as part of the solution; they also suggested that records professionals should demonstrate leadership rather than adopting a passive victim mentality. 
As noted by several authors (Nguyen et al., 2009; McLeod \& Childs, 2013; Edwards, 2007), the implementation of a new recordkeeping system is not always successful, and it is important to look at factors for success and to evaluate how ready organisations are for change. Negative experiences with a system lead to workers finding ways of working outside the system; this means that co-workers will not be able to retrieve the documents they are looking for (Gunnlaugsdottir, 2009). Shepherd and Yeo (2003) warn that where there is high staff turnover, or where staff are retained on short-term contracts, many employees are less likely to be concerned with long-term recordkeeping needs. They go on to say that culture change often includes motivating staff to understand the benefits of good records management, as well as building confidence in new systems.

Smith (2005) argues that some degree of resistance is to be expected as part of organisational change. This resistance can be seen as an obstacle but also as a natural expression of healthy organisational dynamics. Management that seeks to understand rather than just overcome resistance can be part of the process of achieving effective and lasting organisational change. Electronic records management will continue to change because of rapid technological innovation and societal change (McLeod and Childs, 2013), and users will continue to need to adapt. The role of leadership is emphasized by saying that managers need to lead through example by changing themselves (McLeod et al., 2011).

\subsection{The New Zealand Context}

Little research has been undertaken in New Zealand into the human factors affecting recordkeeping. King (2013) investigated the views of staff in local body recordkeeping on their level of responsibility and the extent of formal recordkeeping programmes. She concluded that councils and their record keepers need more guidance about legal rights and responsibilities for council records. In a study on the implementation of EDRMS in New Zealand government organisations Edwards (2007) found that good communication, training, a reliable system, and an understanding of recordkeeping responsibilities contributed to the success of systems. She notes that organisational culture has a significant bearing on the success of EDRMS implementation; and emphasized the role of support from management. She found that management support was only effective if managers were seen to be actively using the recordkeeping system.

Archives New Zealand (2014d) has published the results of their first audit of government recordkeeping, for the years 2011/12; and they found that all 43 offices 
audited had reached a sufficient level of maturity in their compliance with the PRA. They noted an increased shift from physical records to digital records; and they did find weaknesses. Most public offices need more work on the creation and capture of records; and there are also low rates of disposal. Their audit findings showed that the majority of public offices need to review their record management systems, and more than half have included recordkeeping requirements into business processes.

\subsection{Research Design}

This study was conducted using a cross-sectional research design, and its general approach was quantitative. Data was collected from a wide range of records managers across New Zealand, using an online self-completion questionnaire. To benefit from the experiences of records managers a few open ended questions were included. The three text questions were designed to get more insight into the quantitative answers, and potentially yield information for further study. This was a way of measuring current methods, practices and problems across New Zealand, followed by the experiences and insights of different managers who also share strategies and problems in recordkeeping. The designed for total anonymity; of respondent, organisation, type of organisation and recordkeeping system. This should have removed the temptation attempts at social desirability bias (portraying their organisation in a better light) and attempts to please the questionnaire, or acquiescence bias (Leedy and Ormrod, 2013). Questions were altered to avoid asking leading questions - the wording was changed from 'lack of trust' to 'levels of trust' in the survey cover. Other problems Leedy and Ormrod (2013) associate with questionnaires include a low return rate and the fact that the returned questionnaires may not be representative of the original sample. The first 12 questions were multiple choice, and Qualtrics software was set to force responses rather than request them; to be able to use them as statistics, and to generate graphs that could for comparison purposes. The options were to: strongly disagree, disagree, neutral, agree or strongly agree.

\subsection{Ethical Considerations}

Approval for this survey was obtained from the School of Information Management's Human Ethics Committee (HEC) in March of 2014. 
Respondents completing the online-self-completion questionnaire remained anonymous, but were given the option to email the researcher to obtain a report of the collected data. As per requirements of the HEC, collected data may only be viewed by the researcher and their supervisor. No printed documentation was used but all electronic materials will be deleted after two years. These HEC conditions were noted in the survey cover accompanying the questionnaire (see Appendix B.).

\section{Questionnaire}

A copy of the self-completion questionnaire is provided in Appendix A. It consists of twelve multiple choice quantitative questions followed by three text questions. The survey cover (Appendix B) made it plain that the 3 text answers that followed were not compulsory, thereby allowing for differing time constraints.

The survey was anonymous and Qualtrics (2013) online survey software was used to create and manage the survey. It was sent out using the listserv for New Zealand record keepers, nzrecords@lists.vuw.

Pilot testing:

Before sending the survey to the listserv, it was tested on three people with recordkeeping experience. This pilot survey also used Qualtrics. This testing resulted in some changes in the questions, an additional question was created when question 7 was divided into 2 and the text boxes for the qualitative questions were enlarged.

Data collection

The questionnaire and survey cover were sent to the NZ Records listserv during March of 2014, with the first on Monday 10 March, and then 3 reminders on consecutive Fridays.

Survey population

The questionnaire was sent out using the listserv as the best way of contacting the biggest range of records managers across New Zealand. This listerv is open to all recordkeepers in New Zealand (nzrecords@lists.vuw.ac.nz), it was started in 1999 with the aim of serving New Zealand's recordkeeping community. The survey was restricted to records managers in agencies affected by the Public Records Act of 2005, or the Public sector. This group was chosen because they have a different emphasis on recordkeeping from the private sector, while issues of trust in systems affect public and private sectors, the 
public sector have a legal duty to preserve and allow access to information that the private don't. The survey was designed from the point of view of records managers and their perceptions of the levels of trust that staff held in their recordkeeping systems. This view was chosen records professionals take a holistic view of recordkeeping, (McLeod et al., 2011) and understand the responsibilities of PRA. This also prevented self-reporting from staff; self-report data means that people could report what they believe to be true or even what they think we want to hear (Leedy and Ormrod, 2013).

\subsection{Research Limitations}

The research was restricted to New Zealand only, because of time constraints but also because of different legal recordkeeping requirements in different countries. Due to the anonymity of the survey it was also not possible to ask follow-up questions which in some cases would have been useful. This may be an opportunity for further study, though anonymity perhaps resulted in more honesty, especially as both the respondent and their organisation remained anonymous.

The questions asked were as broad as possible, with the aim of being applied to many diverse organisations across the public service. This meant that there was no allowance made for the fact that some public offices have complex business requirements and use a number of digital business systems (Archives New Zealand, 2014d). The Archives New Zealand survey of 2010 (Nielsen, 2010) found that $68 \%$ of public offices employed dedicated recordkeeping staff, and organisations without records managers they would have been excluded from the questionnaire.

\subsection{Research Assumptions}

That due to strict confidentiality as spelled out in the survey cover; (see appendix B) respondents would answer truthfully.

That, due to the way it was disseminated, the survey would reach a random and varied sample of records managers.

That good recordkeeping is important to the respondents.

That all respondents read the survey cover, and are working in the public sector. 


\subsection{Data Analysis}

The survey software Qualtrics uses a range of variables to generate statistics. The multiple choice questions used a rating scale and the data was analyzed for one variable at a time, and the system generated both tables and graphs.

Data from Qualtrics was used to generate additional graphs using Excel.

The open-ended qualitative questions were analyzed separately, and they expanded on or explained some of the multiple choice answers.

\section{Findings}

There was a good response rate, with a quarter of respondents requesting copies of the report, indicating that trust in recordkeeping systems is an important issue to records managers. There were 42 responses, after validation there were 39 complete responses. The sample, judging from requests for reports (as offered in the survey cover, seen in appendix $B$ ) and the answers to the text questions, seems to be representative of the diversity of organisations affected by the PRA.

While the final number is not large, it is similar to the number of organisations (43) audited by Archives New Zealand (2014d) in the 2011/12 audit. Statistics showed it took about 10 minutes to complete, this was the time estimated in the survey invitation and it was judged from the pilot study. The questions were phrased so that answers could present a picture of what is happening in recordkeeping in New Zealand's public sector right now. The recordkeeping system itself; electronic, paper or a combination of the two, was not relevant to this research. The purpose was to sample a variety of organisations across the country. Most respondents answered the three text questions at the end, with question 15 getting the fewest replies at 28.

\subsection{Multiple Choice Questions}

Question 1. I feel that our current recordkeeping system is successful.

The first question was from the records managers' perspective, about their perception and not that of staff, on the success of their recordkeeping system. The literature points to the fact that the technology is adequate for records management (Johnston \& Bowen, 2005). 
Table 1, Question 1.

\begin{tabular}{|c|c|c|c|}
\hline \# & Answer & Response & $\%$ \\
\hline 1 & $\begin{array}{l}\text { Strongly } \\
\text { Disagree }\end{array}$ & 0 & $0 \%$ \\
\hline 2 & Disagree & 6 & $15 \%$ \\
\hline 3 & Neutral & 6 & $15 \%$ \\
\hline 4 & Agree & 23 & $59 \%$ \\
\hline 5 & $\begin{array}{l}\text { Strongly } \\
\text { Agree }\end{array}$ & 4 & $10 \%$ \\
\hline & Total & 39 & $100 \%$ \\
\hline
\end{tabular}

Figure 2, Question 1.

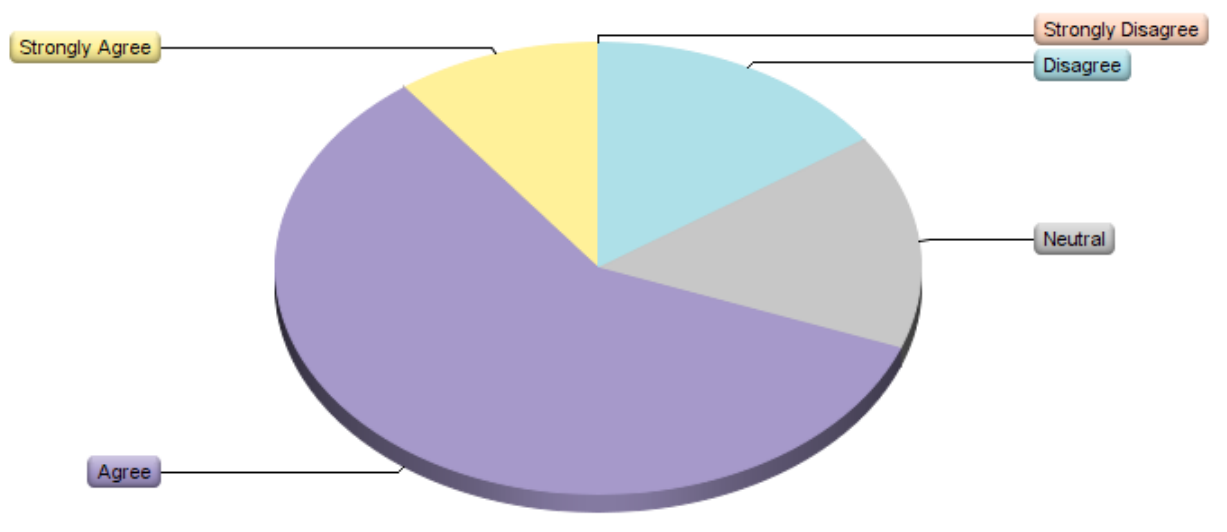

More than half, or $69 \%$ agreed that their system was successful, of those $10 \%$ strongly agreed and $15 \%$ remained neutral while only $15 \%$ disagreed. That leaves $75 \%$ positive or neutral. 
Question 2. Our current recordkeeping system is trusted by employees.

This question was asked to discover if there was a difference between the number of records managers who felt their system was adequate, and the perception of staff. Various authors (Oliver \& Foscarini, 2014; Gunnlaugsdottir, 2009) have identified the need for trust, as a factor in compliance.

Table 2, Question 2.

\begin{tabular}{|c|l|c|c|c|}
\hline$\#$ & Answer & Response & $\%$ \\
\hline 1 & $\begin{array}{l}\text { Strongly } \\
\text { Disagree }\end{array}$ & 1 & $3 \%$ \\
\hline 2 & Disagree & 7 & $18 \%$ \\
\hline 3 & Neutral & 8 & $21 \%$ \\
\hline 4 & Agree & 22 & $56 \%$ \\
\hline 5 & $\begin{array}{l}\text { Strongly } \\
\text { Agree }\end{array}$ & 1 & $3 \%$ \\
\hline & Total & 39 & $100 \%$ \\
\hline
\end{tabular}

Figure 3, Question 2

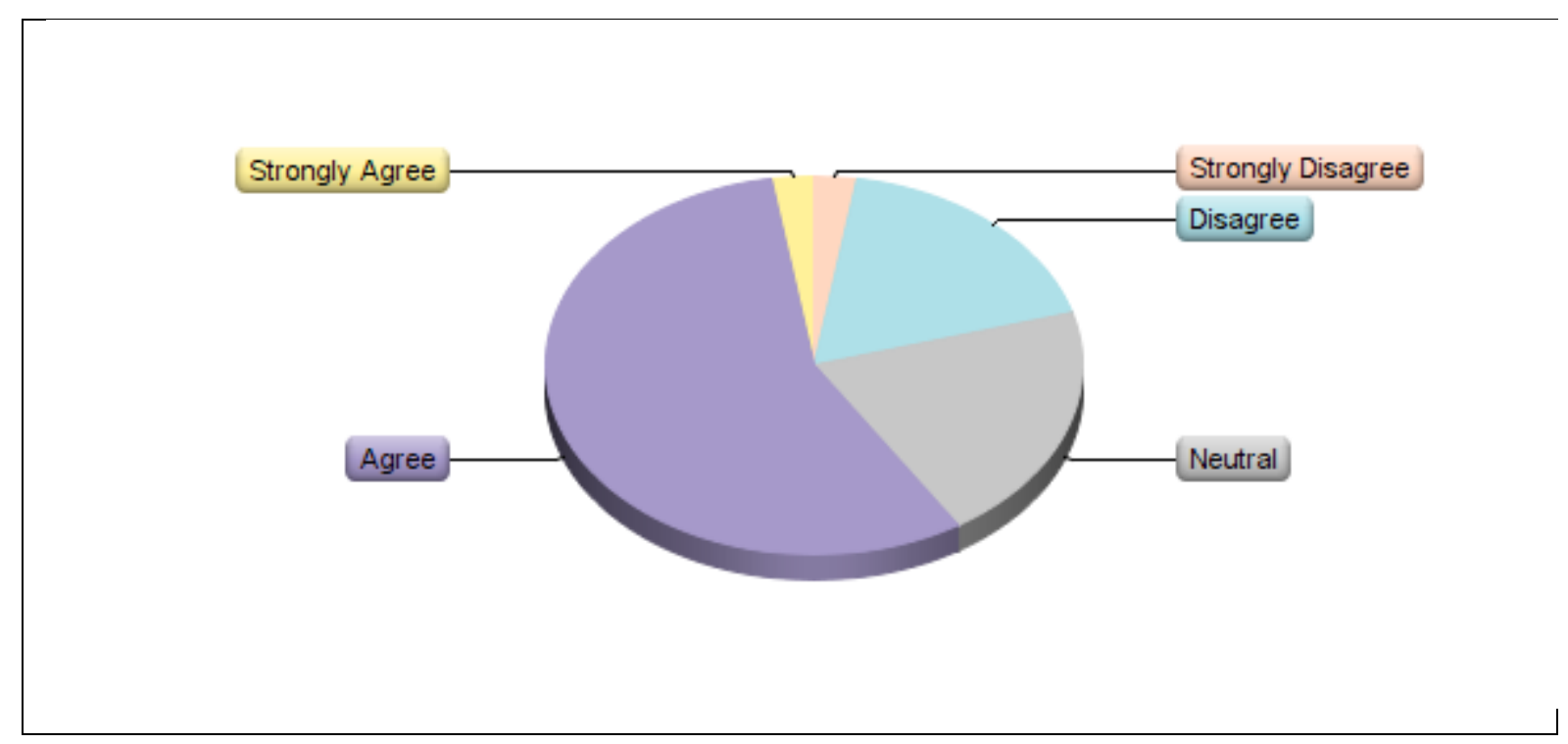

$59 \%$ felt their staff trusted the system, with only one respondent (3\%) strongly agreeing . and 1 respondent strongly disagreed, pointing to a strong distrust in their system? 
Question 3. Lack of trust in our recordkeeping system impacts on employee use of the system.

Lack of trust was not asked until the third question to avoid asking leading questions: trust has shown to be an issue by several authors (Johnston and Bowen, 2005; Gunnlaugsdottir, 2009; Oliver \& Foscarini, 2014) with poorly kept records having potentially bad consequences (Thurston, 2012).

Table 3, Question 3.

\begin{tabular}{|c|l|c|c|c|}
\hline$\#$ & Answer & Response & $\%$ \\
\hline 1 & $\begin{array}{l}\text { Strongly } \\
\text { Disagree }\end{array}$ & 1 & $3 \%$ \\
\hline 2 & Disagree & 5 & $13 \%$ \\
\hline 3 & Neutral & & 4 & $10 \%$ \\
\hline 5 & Agree & 18 & $46 \%$ \\
\hline 5 & $\begin{array}{l}\text { Strongly } \\
\text { Agree }\end{array}$ & 11 & $28 \%$ \\
\hline & Total & 39 & $100 \%$ \\
\hline
\end{tabular}

Figure 4, Question 3.

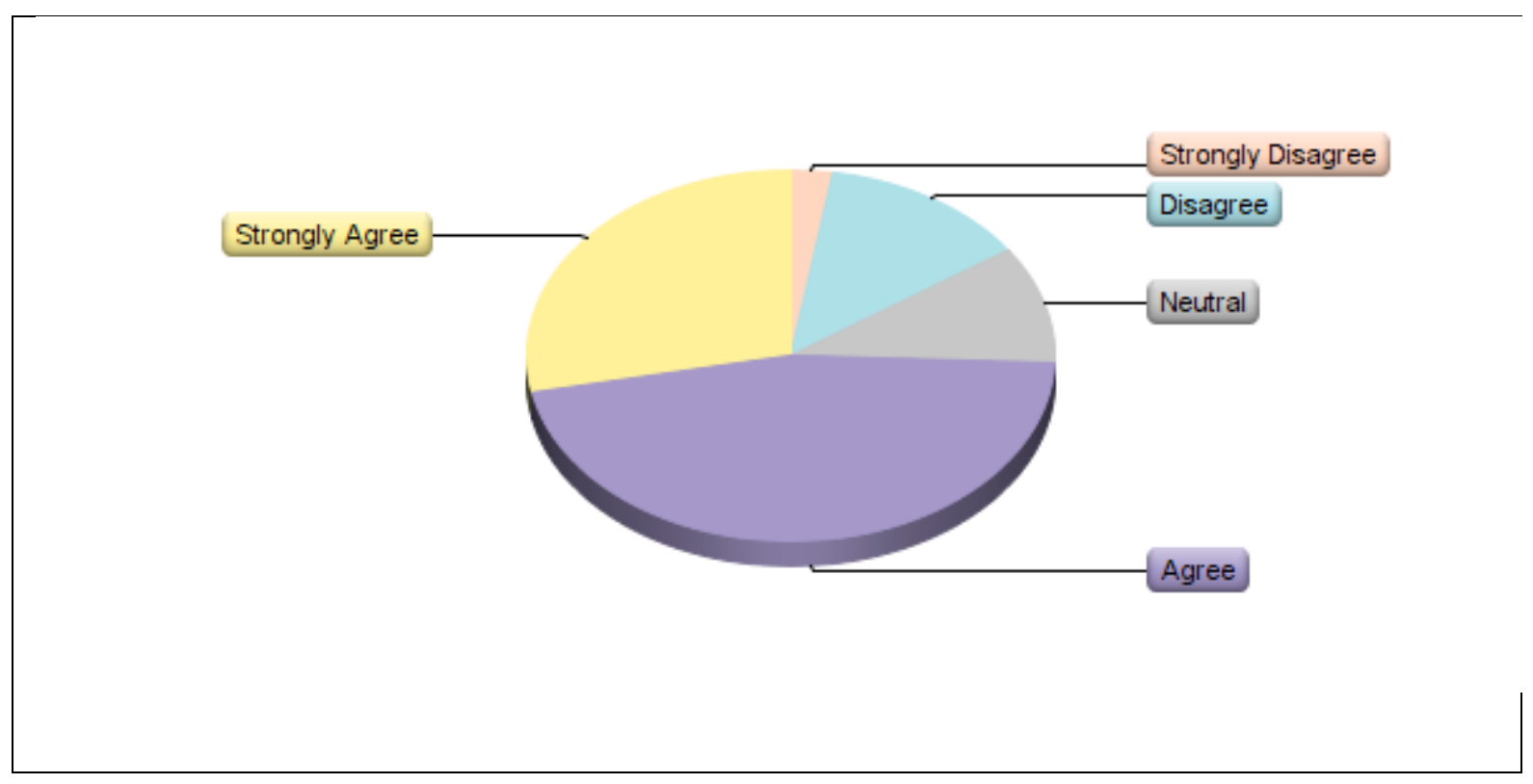


$74 \%$ agreed or strongly agreed that lack of trust in the system impacted on employee use of the system. $13 \%$ disagreed and $10 \%$ stayed neutral. Again one respondent strongly disagreed.

Question 4. Our employees have received sufficient training in our recordkeeping system.

Inadequate training has been mentioned repeatedly as a potential cause of lack of trust (Basoum, 2006; Di Biagio and Ibiricu, 2008). Training has also been identified (Johnston and Bowen, 2005) as an opportunity to allay fears.

Table 4, Question 4.

\begin{tabular}{|c|l|c|c|c|}
\hline$\#$ & Answer & Response & $\%$ \\
\hline 1 & $\begin{array}{l}\text { Strongly } \\
\text { Disagree }\end{array}$ & & 0 & $0 \%$ \\
\hline 2 & Disagree & 9 & $23 \%$ \\
\hline 3 & Neutral & 12 & $31 \%$ \\
\hline 5 & Agree & 13 & $33 \%$ \\
\hline & Strongly & Agree & 5 & $13 \%$ \\
\hline & Total & 39 & $100 \%$ \\
\hline
\end{tabular}


Figure 5, Question 4.

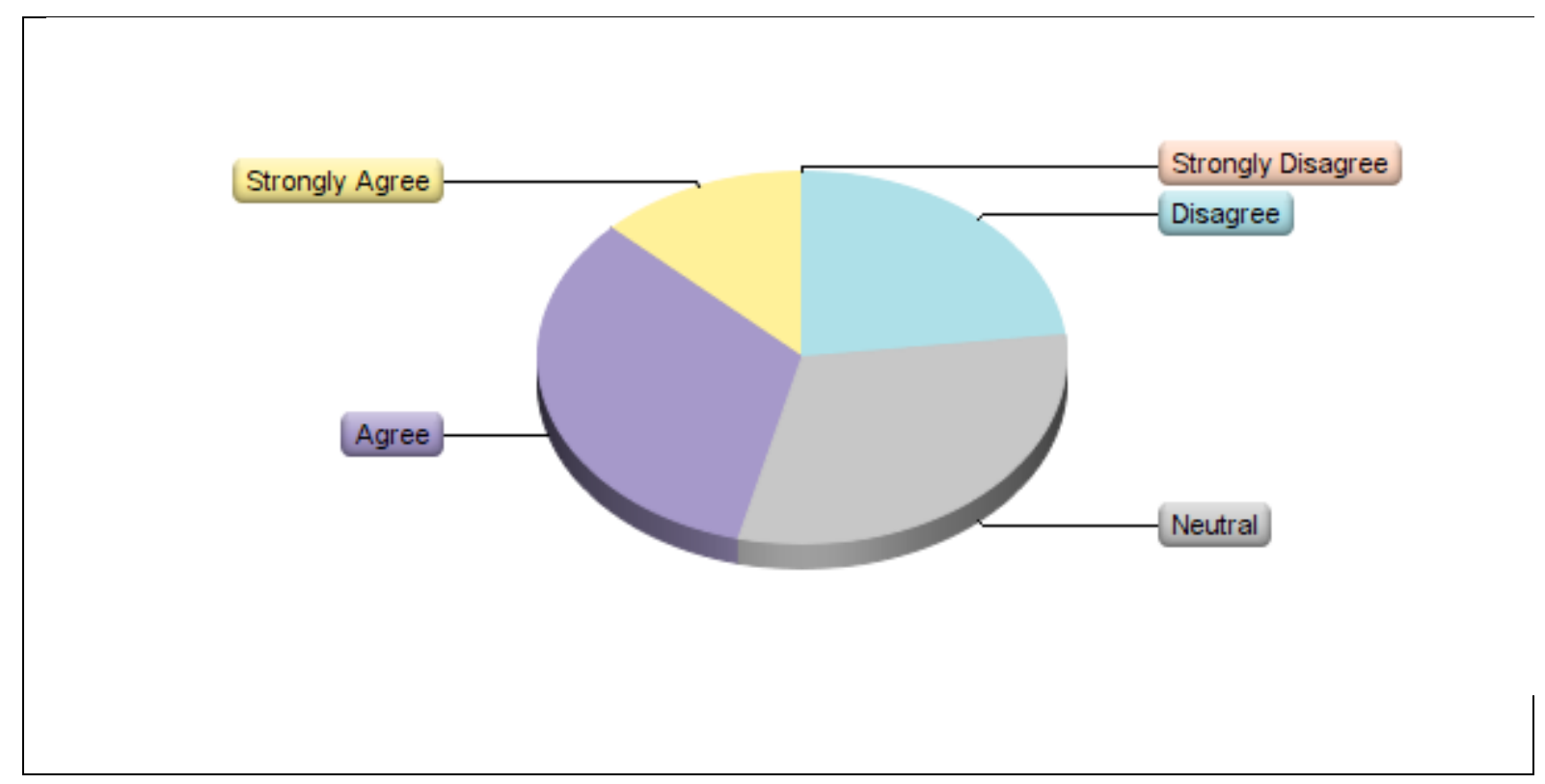

The question of sufficient training had almost half or $46 \%$ agreeing that staff had received sufficient training in the system. $31 \%$ remained neutral and $23 \%$ disagreed.

Question 5. Our employees feel confident using our recordkeeping system.

Adequate training is believed to enhance confidence (Di Biagio \& Ibiricu, 2008;

Gunlaughsdottir, 2008) so this question was asked to see if there was a correlation.

Table 5, Question 5.

\begin{tabular}{|c|l|c|c|c|}
\hline$\#$ & Answer & Response & $\%$ \\
\hline 1 & $\begin{array}{l}\text { Strongly } \\
\text { Disagree }\end{array}$ & & 0 & $0 \%$ \\
\hline 2 & Disagree & & 11 & $28 \%$ \\
\hline 3 & Neutral & 13 & $33 \%$ \\
\hline 4 & Agree & 14 & $36 \%$ \\
\hline 5 & $\begin{array}{l}\text { Strongly } \\
\text { Agree }\end{array}$ & 1 & $3 \%$ \\
\hline & Total & 39 & $100 \%$ \\
\hline
\end{tabular}


Figure 6, Question 5.

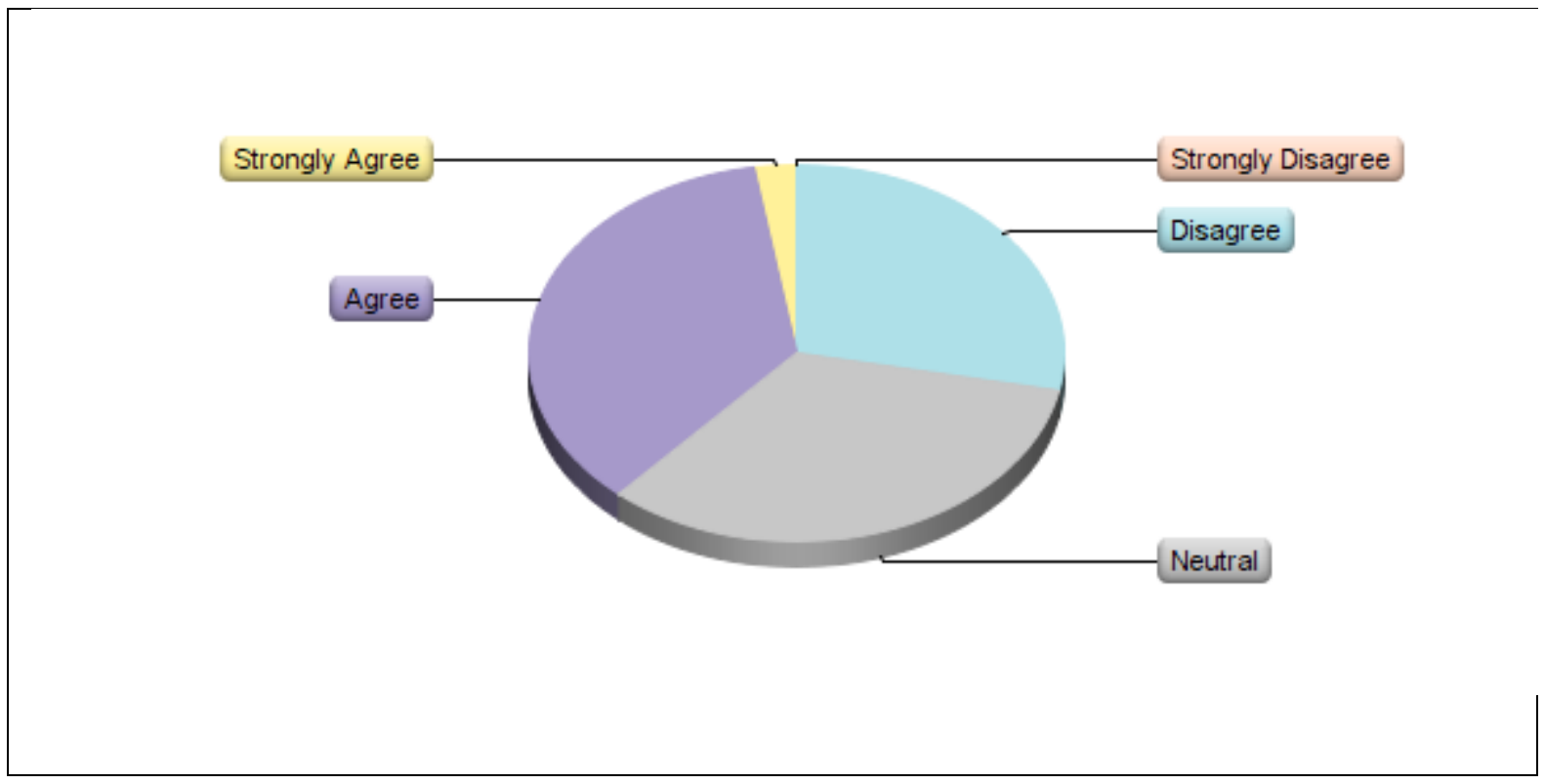

Only one records manager strongly agreed to this question, with $39 \%$ agreeing in total and $28 \%$ or 11 records managers disagreed

Question 6. Employees at our organisation understand the importance of efficient recordkeeping.

This question examines staff attitudes and motivation as well as giving an insight into different organisational cultures and levels of training. 
Table 6, Question 6.

\begin{tabular}{|c|l|c|c|}
\hline$\#$ & Answer & Response & $\%$ \\
\hline 1 & $\begin{array}{l}\text { Strongly } \\
\text { Disagree }\end{array}$ & 0 & $0 \%$ \\
\hline 2 & Disagree & & $21 \%$ \\
\hline 3 & Neutral & 14 & $36 \%$ \\
\hline 4 & Agree & 14 & $36 \%$ \\
\hline 5 & $\begin{array}{l}\text { Strongly } \\
\text { Agree }\end{array}$ & 3 & $8 \%$ \\
\hline & Total & 39 & $100 \%$ \\
\hline
\end{tabular}

Figure 7, Question 6

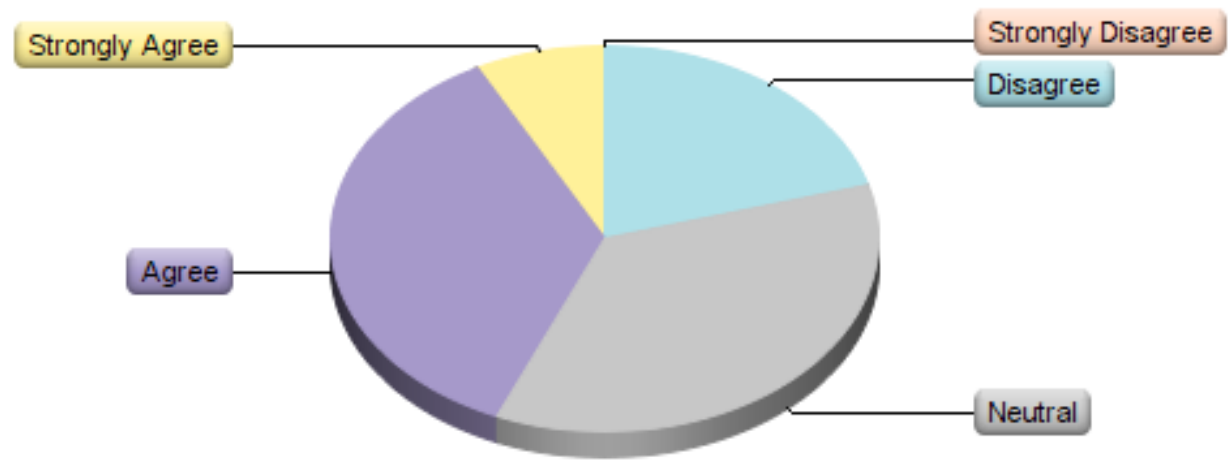

More respondents agreed than disagreed with this with $44 \%$ feeling that staff understand the importance of efficient recordkeeping, $21 \%$ disagreed while $36 \%$ remained neutral.

Question7. My manager understands and trusts the recordkeeping system 
The role of management involvement is emphasized in the literature (Di Biago \&lbiricu, 2008; Gunnlaugsdottir 2009), and the point that managers need to lead by changing themselves was made by McLeod et al. (2011).

Table 7, Question 7.

\begin{tabular}{|c|l|c|c|c|}
\hline$\#$ & Answer & & Response & $\%$ \\
\hline 1 & $\begin{array}{l}\text { Strongly } \\
\text { Disagree }\end{array}$ & & 0 & $0 \%$ \\
\hline 2 & Disagree & & 3 & $8 \%$ \\
\hline 3 & Neutral & & 6 & $15 \%$ \\
\hline 4 & Agree & & 19 & $49 \%$ \\
\hline 5 & $\begin{array}{l}\text { Strongly } \\
\text { Agree }\end{array}$ & 11 & $28 \%$ \\
\hline & Total & 39 & $100 \%$ \\
\hline
\end{tabular}

Figure 8, Question 7.

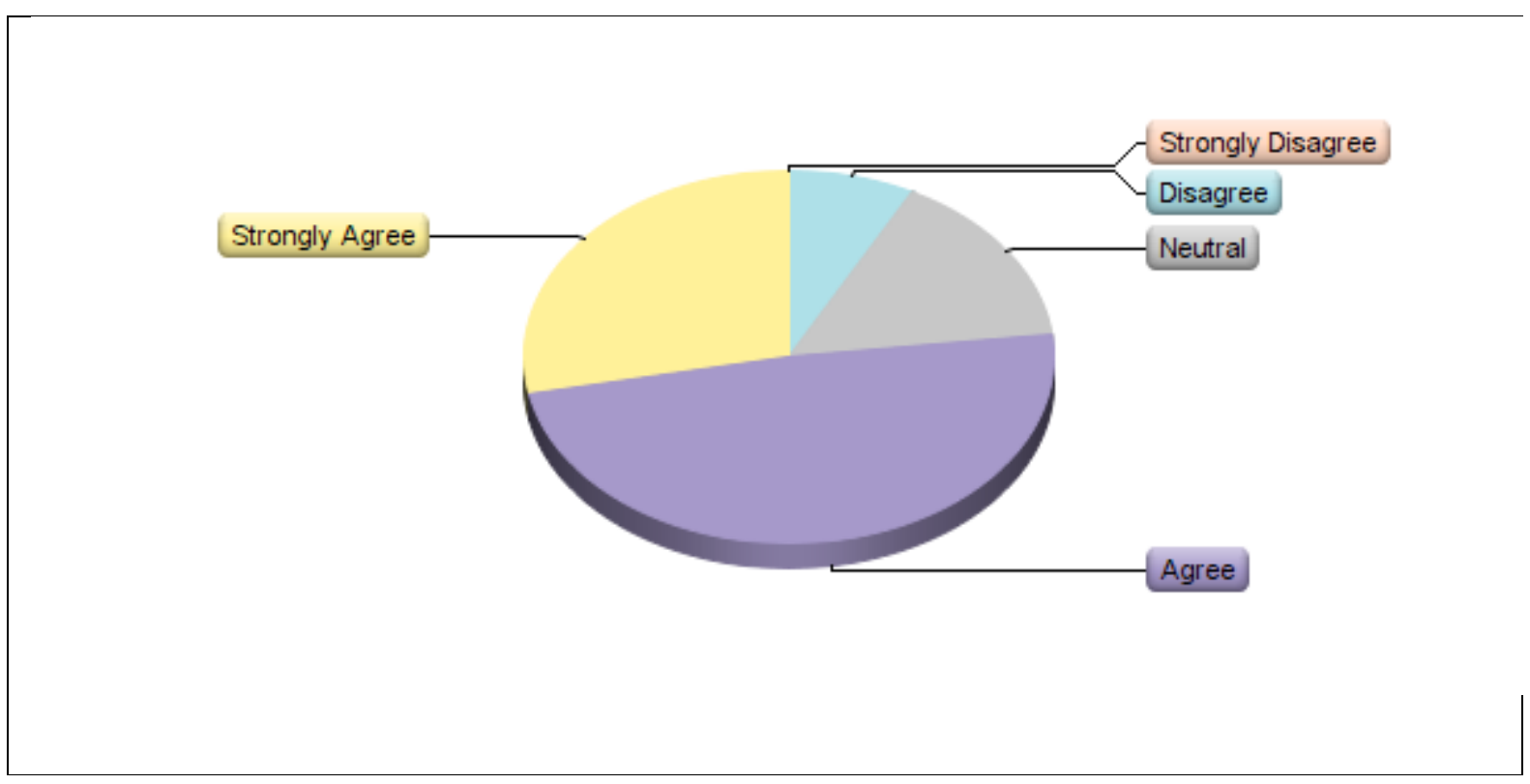

The answer here was strongly positive with $77 \%$ of staff noting that their manager understands and trusts the system. 15\% remained neutral and 3 respondents or $8 \%$ disagreed, though none disagreed strongly. 
Question 8. My manager actively promotes the use of our recordkeeping system.

This question was asked because managers can promote a system they don't understand; and because management support has been stressed as vital by several authors (Di Biago \& Ibiricu, 2008; Gunnlaugsdottir 2009; Edwards, 2007).

Table 8, Question 8.

\begin{tabular}{|c|l|c|c|c|}
\hline$\#$ & Answer & Response & $\%$ \\
\hline 1 & $\begin{array}{l}\text { Strongly } \\
\text { Disagree }\end{array}$ & 0 & $0 \%$ \\
\hline 2 & Disagree & 5 & $13 \%$ \\
\hline 3 & Neutral & 5 & $13 \%$ \\
\hline 5 & $\begin{array}{l}\text { Agree } \\
5\end{array}$ & $\begin{array}{l}\text { Strongly } \\
\text { Agree }\end{array}$ & 14 & $36 \%$ \\
\hline & Total & 15 & $38 \%$ \\
\hline
\end{tabular}

Figure 9, Question 8.

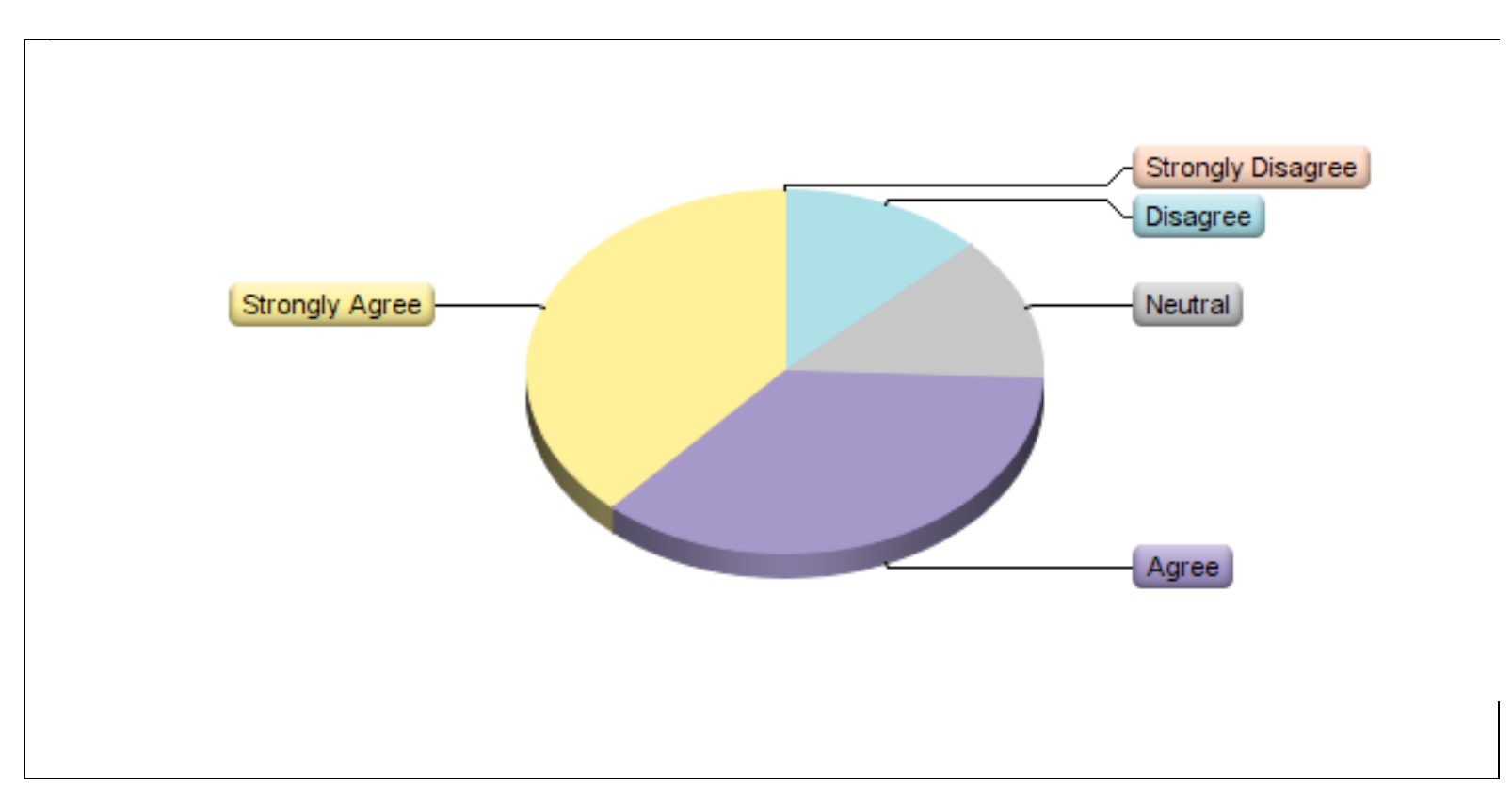


$74 \%$ stated that managers were active in promoting the system. This corresponds well with $77 \%$ above who felt that their managers understand and trust their system. $13 \%$ remained neutral and $13 \%$ disagreed.

Question 9. In my organisation management attitudes affect employee compliance in recordkeeping.

This was asked from the unique viewpoint of the records manager who will have had the experience to see what affects recordkeeping behaviour (McLeod et al., 2011).

Table 9, Question 9.

\begin{tabular}{|c|l|c|c|c|}
\hline$\#$ & Answer & & Response & $\%$ \\
\hline 1 & $\begin{array}{l}\text { Strongly } \\
\text { Disagree }\end{array}$ & & 0 & $0 \%$ \\
\hline 2 & Disagree & & 0 & $0 \%$ \\
\hline 3 & Neutral & 1 & $3 \%$ \\
\hline 5 & Agree & 23 & $59 \%$ \\
\hline 5 & Strongly & Agree & 15 & $38 \%$ \\
\hline & Total & 39 & $100 \%$ \\
\hline
\end{tabular}


Figure 10, Question 9.

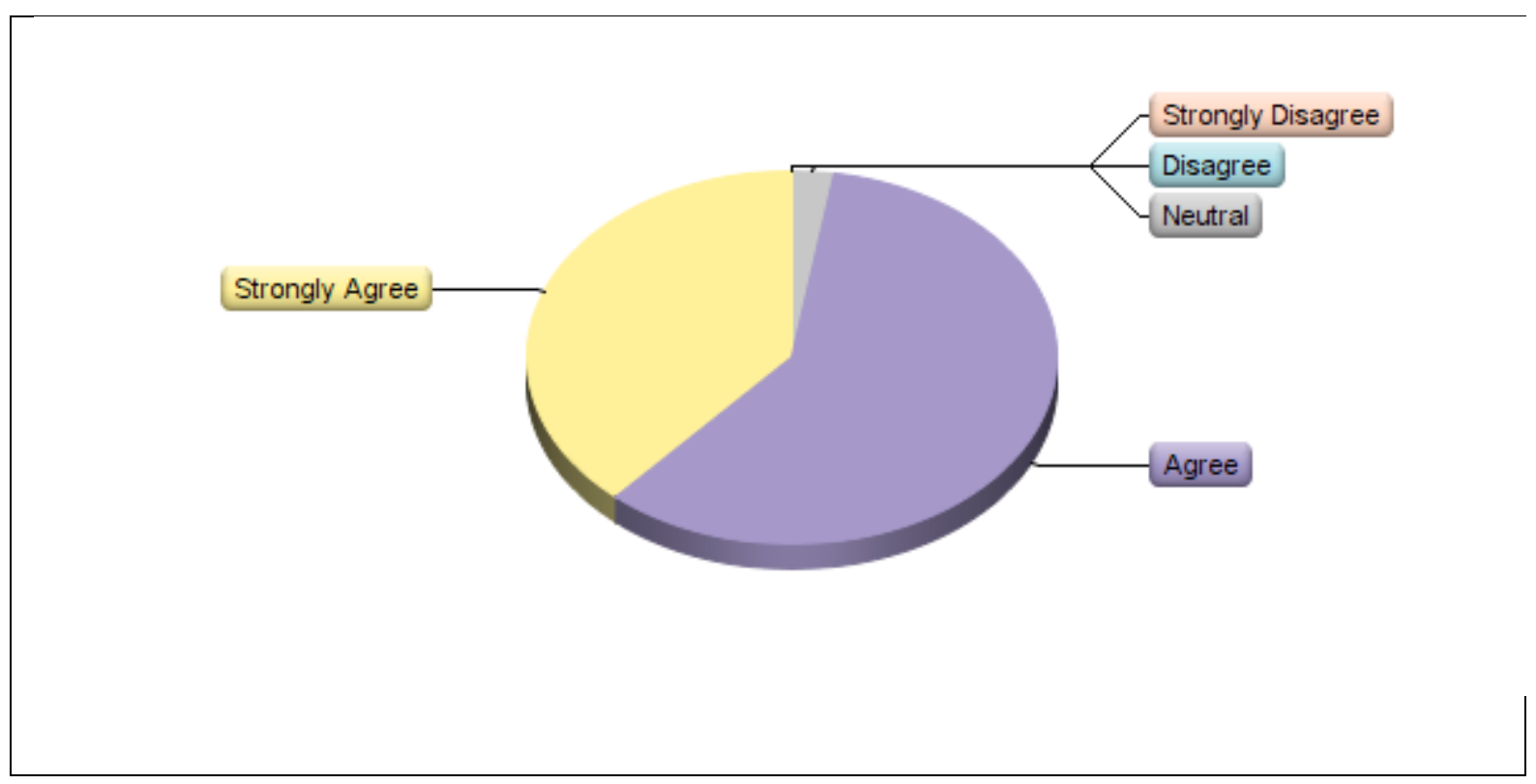

Almost all had found that attitudes from management (97\%) affected compliance in recordkeeping. Only 1 respondent returned a neutral response and none disagreed.

Question 10. Changes in recordkeeping systems affect employee trust in the systems.

Various authors (Nguyen et al., 2009; McLeod \& Childs, 2013; Edwards, 2007) have identified changes in systems as a potential cause for loss of trust.

Table 10, Question 10.

\begin{tabular}{|c|l|c|c|c|}
\hline$\#$ & Answer & Response & $\%$ \\
\hline 1 & $\begin{array}{l}\text { Strongly } \\
\text { Disagree }\end{array}$ & & 0 \\
\hline 2 & Disagree & & 6 & $15 \%$ \\
\hline 3 & Neutral & 8 & $21 \%$ \\
\hline 4 & Agree & 18 & $46 \%$ \\
\hline 5 & $\begin{array}{l}\text { Strongly } \\
\text { Agree }\end{array}$ & 7 & $18 \%$ \\
\hline & Total & 39 & $100 \%$ \\
\hline
\end{tabular}


Figure 11, Question 10.

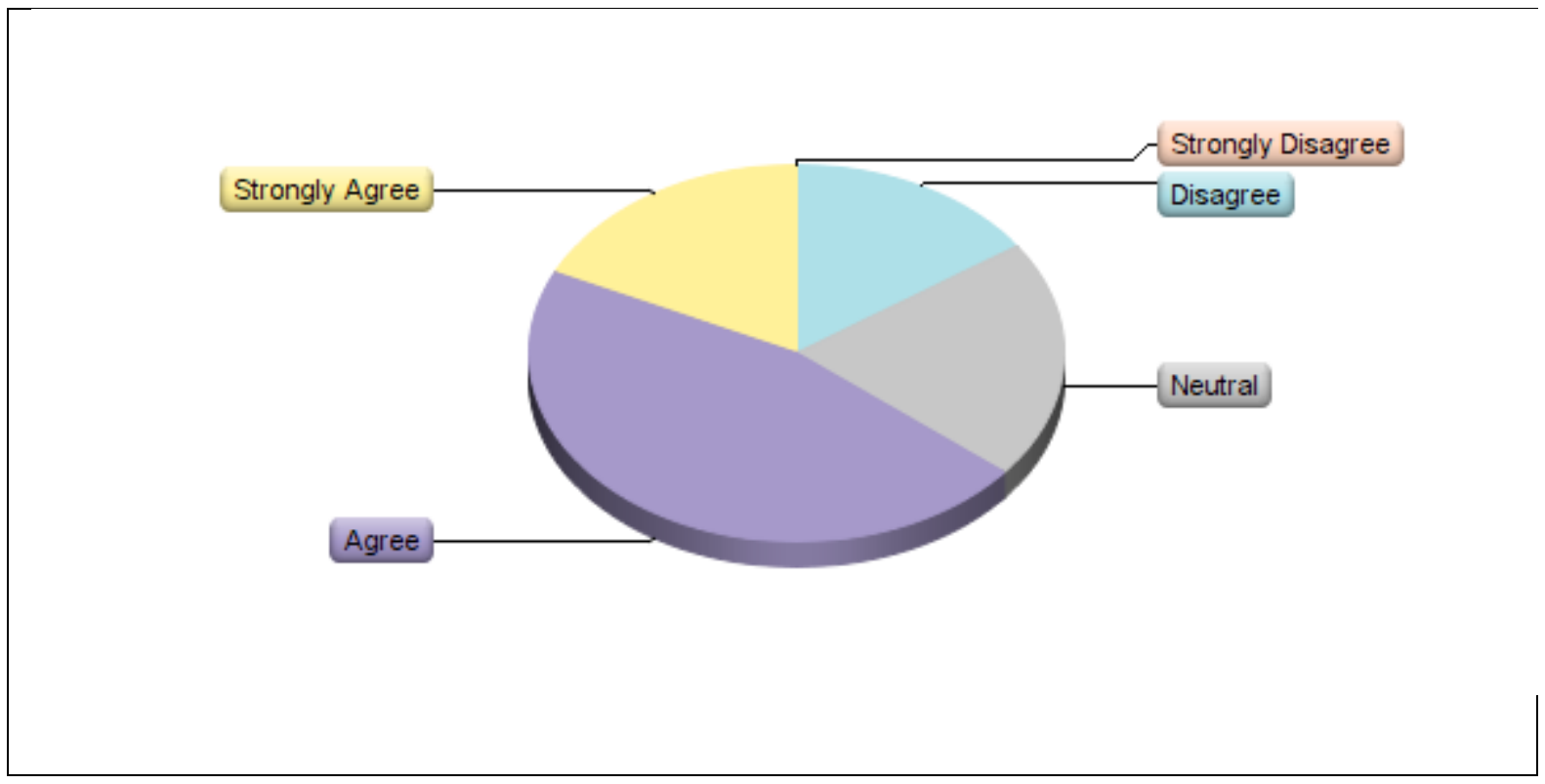

Changes in systems were found to affect trust by most (64\%) while $21 \%$ remained neutral , and $15 \%$ disagreed.

Question 11. Employees are confident that our recordkeeping system helps them to comply with the aims of the PRA.

All public offices in New Zealand are subject to the PRA (Archives New Zealand, 2014a), and should be maintaining their records to the standards expected by the act. If staff don't understand why they have to follow procedures, they are less likely to comply (McLeod, et al., 2011). 
Table 11, Question 11.

\begin{tabular}{|c|c|c|c|}
\hline \# & Answer & Response & $\%$ \\
\hline 1 & $\begin{array}{l}\text { Strongly } \\
\text { Disagree }\end{array}$ & 1 & $3 \%$ \\
\hline 2 & Disagree & 2 & $5 \%$ \\
\hline 3 & Neutral & 20 & $51 \%$ \\
\hline 4 & Agree & 12 & $31 \%$ \\
\hline 5 & $\begin{array}{l}\text { Strongly } \\
\text { Agree }\end{array}$ & 4 & $10 \%$ \\
\hline
\end{tabular}

Figure 12, Question 11.

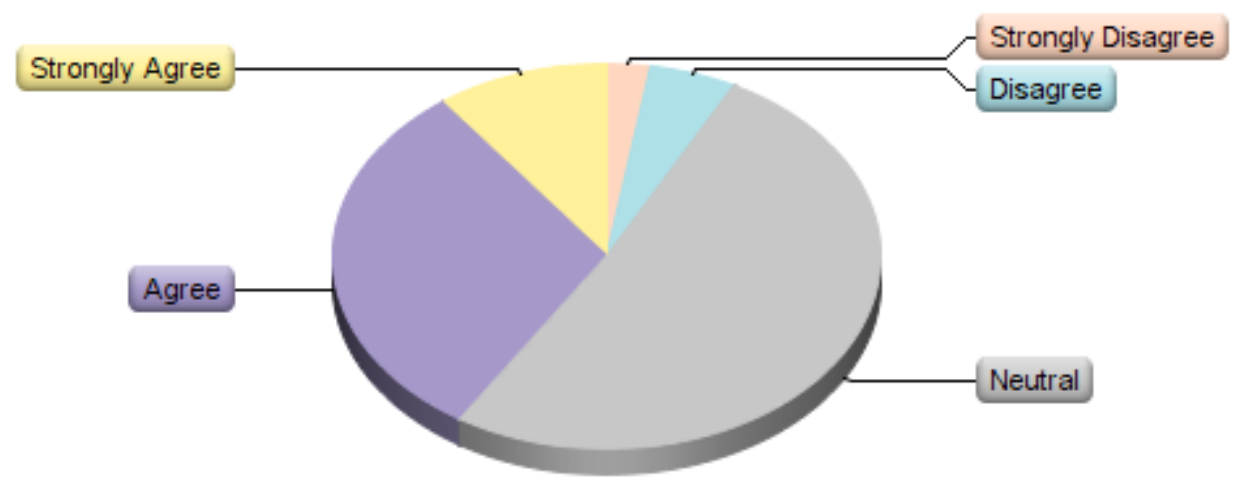

Most records managers remained neutral $51 \%$ on this question, three or $8 \%$ disagreed or strongly disagreed, $31 \%$ agreed and $10 \%$ strongly agreed.

Question 12. Employees are confident that they would be able to retrieve information added to our recordkeeping system in five years' time.

What do they trust it to do? This question was suggested by Oliver and Foscarini (2014) as a way to measure trust in recordkeeping systems. 
Table 12, Question 12.

\begin{tabular}{|c|l|c|c|c|}
\hline$\#$ & Answer & Response & $\%$ \\
\hline 1 & $\begin{array}{l}\text { Strongly } \\
\text { Disagree }\end{array}$ & 1 & $3 \%$ \\
\hline 2 & Disagree & 6 & $15 \%$ \\
\hline 3 & Neutral & 10 & $26 \%$ \\
\hline 4 & Agree & 15 & $38 \%$ \\
\hline 5 & Strongly & Agree & 79 & $18 \%$ \\
\hline & Total & & 39 & $100 \%$ \\
\hline
\end{tabular}

Figure 13, Question 12.

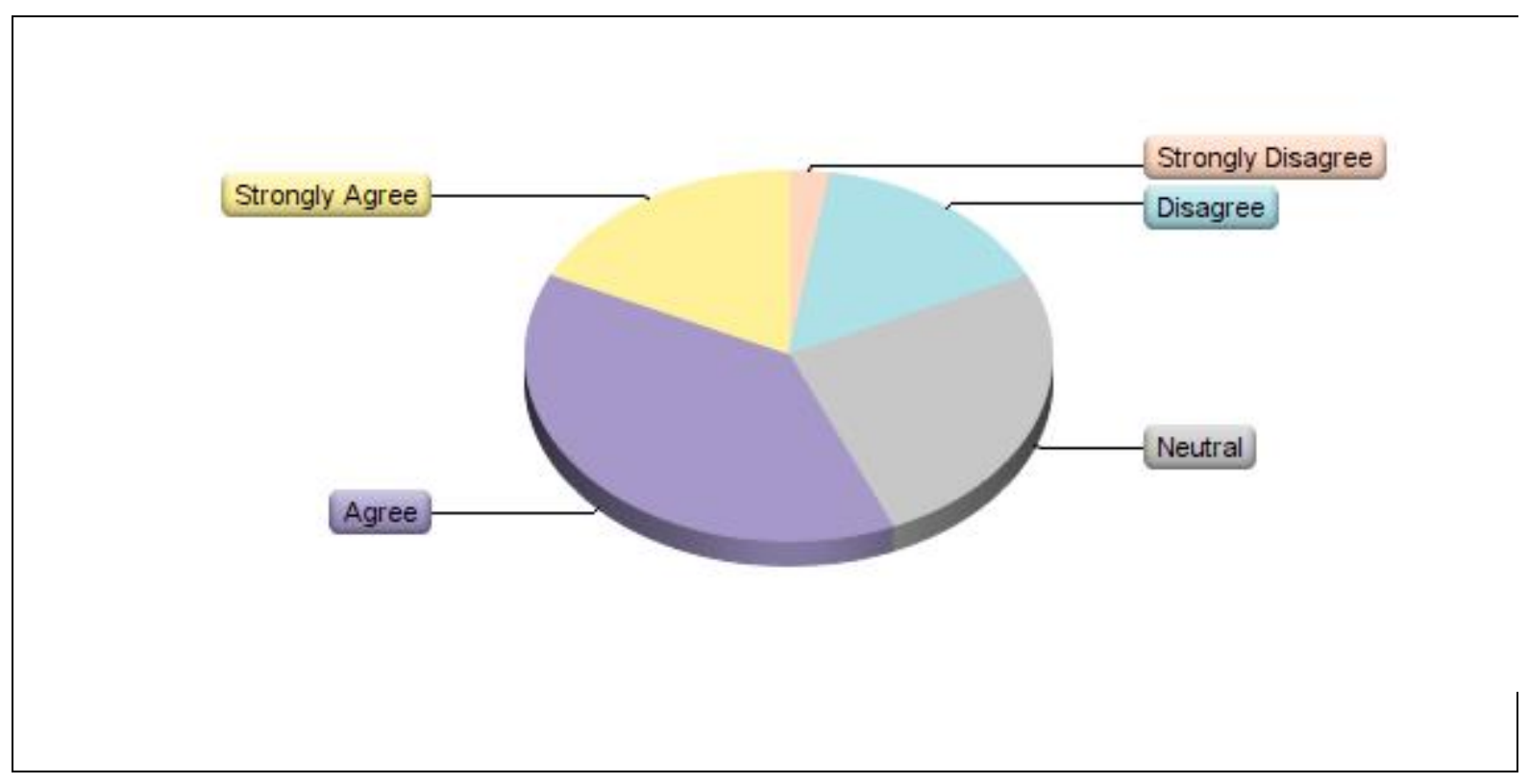

Most (56\%) felt that the staff trusted the system to deliver this, $26 \%$ remained neutral and $18 \%$ disagreed. Of those who agreed, 7 strongly agreed and of those who disagreed, 1 strongly disagreed. 
Figure 14, Questions 1-12.

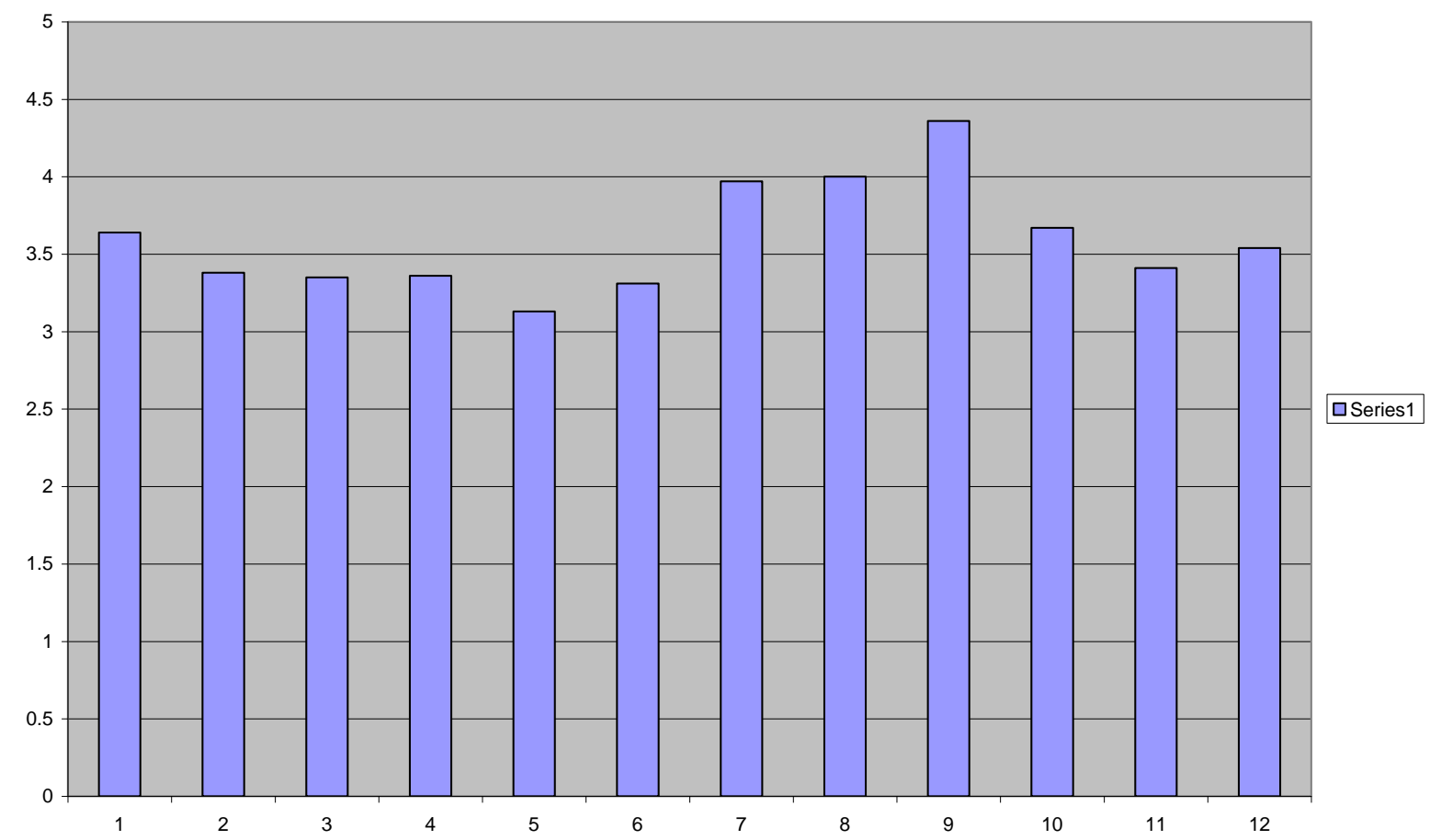

Figure 14 shows the mean statistical value of each of the questions converted to ratio testing for a ratio or scale. There is a symmetry of categories and the midpoint is neutral. Each question is ranked with:

Strongly disagree $=1$. Disagree $=2$, Neutral $=3$, Agree $=4$, Strongly agree $=5$

Even though responses were mixed all means were between 3 and 5, or between neutral and strongly agree. The strongest positive response was question 9, management, and the weakest was question five, confidence.

When contrasting these answers between records managers who felt their systems were successful, and those who did not, some strong differences were found. 
Figure 15, Successful versus not successful recordkeeping systems

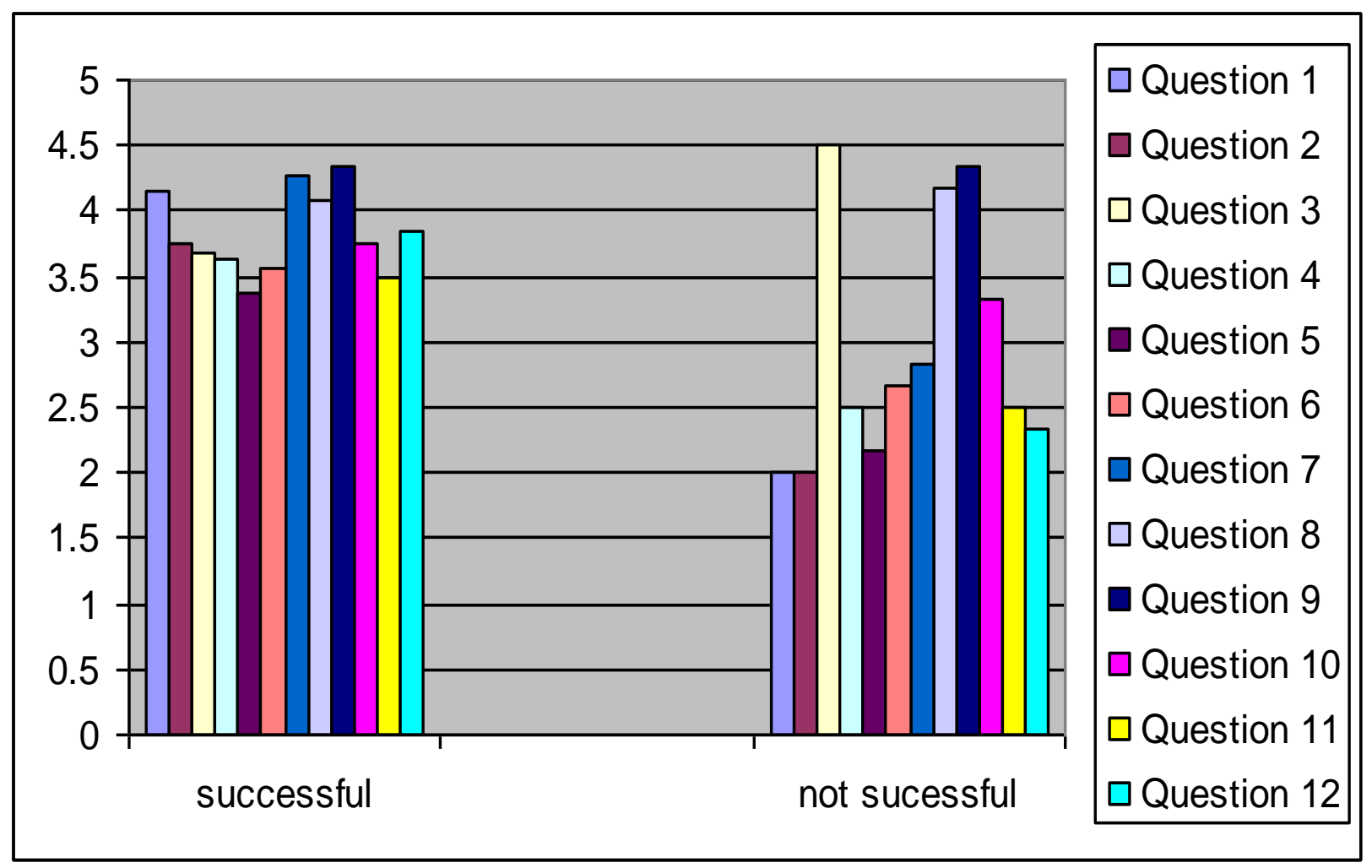

Figure 15 demonstrates the difference in answers between recordkeepers who believe their system is successful; and those who believe it is not successful. The mean is 3 , and for the averages for where the records manager feels the system is successful is above three, or positive. The average where the system is not seen as less successful is mainly below three or negative. The strongest difference between these two groups is in question 3, about lack of trust impacting on employee use of the system. Question 8 is similar in both groups, implying that the managers promotes the systems in both, but more managers understand and trust the system (question 7) in successful recordkeeping. Attitudes from management are seen to affect both groups equally (question 9) and changes in systems affect both groups, but less in the less successful group. The records managers of the less successful systems were negative (on average) about sufficient training, staff confidence in the system, trust in the system, staff understanding of the importance of efficient recordkeeping, compliance with the PRA and retrieval. Amongst the successful group the least positive 
response was about staff feeling confident about using the system, and compliance with the PRA.

\subsection{Text questions}

These questions were worded to give respondents a chance to elaborate on their answers to the twelve multiple choice questions. Questions 13 and 14 were designed to shed light on the organisational culture and specifically recordkeeping cultures within different organisations. It was hoped that anonymity would enable records managers to say things they wouldn't normally say about their organisations.

Question 13. Please share the most effective strategy you have found to promote trust in your organisations' recordkeeping system.

Thirty six record keepers responded to this question, several with more than one strategy. Ongoing support, demonstration of effectiveness of the system, and training and communication were mentioned by most. Rapid response to problems was mentioned as fostering trust. As were automating the system in such a way that it is effortless to comply with the PRA, and ensuring that the systems are embedded into business processes and the way people work. The use of recordkeeping champions, or peer pressure, was also found to be effective by some.

Question 14. Please share some of the ways employees in your organisation have found to bypass the system.

Trust is such a difficult concept to define or measure, that this question examines the symptoms of mistrust. The 36 records managers who answered this question listed a variety of personal 'hoarding of information' methods amongst staff. These included saving records to desktops, saving to shared or personal drives, using the cloud, using usb sticks and external hardrives as well as email. Some, more adventurously, were altering classification structure and changing metadata. Only one felt that any bypassing of the system would be unethical, and was unlikely to be deliberate. 
Question 15. Do you have any other comments relating to employee trust in recordkeeping systems?

This question was asked to give respondents an opportunity to elaborate further on issues that are important to them. It received the smallest number of responses, at 28, possibly because their points had been addressed in the previous two questions. Five respondents returned to issues with management, while another pointed out the fact that digitising everything was not magic. Several respondents stated that trust can disappear much faster than it takes to build it.

\section{Discussion}

This research has shown that record managers do identify lack of trust in recordkeeping systems as a barrier to compliance in recordkeeping; but this varies from one public service organisation to another. There are many different organisations affected by the PRA in New Zealand, and this is reflected in diverse responses to the questionnaire. Some organisations, like the National Library and Archives New Zealand, will be staffed by information professionals; who may be expected to have different attitudes to recordkeeping from that found in some other public service organisations. The insight of records managers into the behaviour of recordkeeping of staff is valuable because they have a holistic view of recordkeeping in their organisation (McLeod, et al., 2011). Most respondents felt that their recordkeeping system is adequate, but fewer felt it was trusted by staff, and even fewer felt staff trusted it for long-term retrieval. Various factors were felt to contribute to trust; management attitudes and support were identified as crucial, as were training, communication and on-going support. Less than half felt that their staff understood the importance of efficient recordkeeping, and most remained neutral on staff attitude to the PRA. While most respondents found that changes in systems could be a factor in loss of trust, several disagreed. A variety of hoarding of information methods were identified as well as a variety of ways to encourage trust and achieve compliance.

Johnston and Bowen (2005) found that the technology for recordkeeping was adequate, and this was borne out by most record keepers feeling that their systems were successful (Table 1). However 15\% percent did not; and in the audit for 2011/2012 by Archives New Zealand (2014 d) it was noted that a number of organisations were 
undertaking upgrades, or implementing new recordkeeping systems. Although it was not possible to find out how many of these respondents were planning to upgrade systems, it can be assumed that some are. More records managers than staff trusted their current system, and most (74\%) felt that lack of trust impacted staff use of the system. This was higher in organisations where recordkeepers did not believe that their system was successful (Figure 15). Thurston (2012) warned that poor recordkeeping could have potentially serious consequences, and that if records are not managed professionally their integrity can be compromised. Nguyen et al. (2009) found that ensuring that employees use a system effectively is very difficult. To alleviate problems like this it is important to find the factors that contribute to the building and destruction of trust in recordkeeping systems. Several records managers noted that trust is slow to build and that there is no silver bullet.

"People will trust what can be demonstrated to work efficiently"

"If the system is perceived as unstable, then there is a natural reluctance to take the risk of adding your work".

"I think fixing bugs and errors is the most important. If people experience ongoing issues and these are not remedied it is a permanent barrier to usage"

Several mentioned that once trust is lost, it is very hard to regain.

Of the respondents most, or $59 \%$, felt that their staff trusted the system, while $69 \%$ of records managers felt that their systems were adequate; the comparison between these can be seen in Figure 15. The retrieval function of a recordkeeping is a part of continuum theory; and as Downing (2006) states, saving information correctly so that it can be retrieved is the primary goal of document management. The question of staff trusting a system for the retrieval of a document in five years' time was suggested by Oliver and Foscarini (2014, p.148) as a way to gain insight on the extent to which staff trust recordkeeping systems. Most (56\%) felt that the staff trusted the system to deliver this; $26 \%$ remained neutral, and $18 \%$ disagreed. As shown in Figure 15, records managers with successful systems were more positive on this question, and those with less successful systems more negative. Retrieval was also a part of the Archives New Zealand (2014d) audit where they found that $60 \%$ of organisations had practices in place to ensure the records would be accessible and retrievable when required.

The role of management, especially senior management, has been strongly 
emphasized in the literature (Di Biago \& Ibiricu, 2008; Gunnlaugsdottir, 2009) and their support is considered vital (Shepherd \&Yeo, 2003) to the success of a records management programme. Various factors were identified as contributing to trust in the systems but the strongest results were about management, where almost all respondents agreed (and none disagreed) that attitudes from management affect employee compliance in record keeping, this can be seen in Figure 14. Most were positive about attitudes from management with only $8 \%$ feeling that their manager did not understand and trust their system and $13 \%$ feeling that they did not actively promote its use. This implies that most of the participants receive and appreciate support from management in record keeping. In Figure 15, comparing systems viewed as successful and unsuccessful, both groups felt that the manager promoted the recordkeeping system, but in the less successful system fewer felt that the managers understood and trusted it. Edwards (2007) also found that management support was more effective when managers were seen to by using the system. As mentioned by McLeod et al. (2011) leaders need to facilitate change by changing themselves. The old adage 'a fish rots from the head down' is often applied to management, particularly poor management, but Farazmand $(2014$, p.368) states that: “... it can also thrive in the same directional manner if the leader at the top sets the example for all those who follow." Respondents felt so strongly about the role of senior management that it was mentioned repeatedly in the text answers. Comments included:

"Employee trust will be reduced if they do not see management using the system effectively.... Inconsistency hampers the message that the system can be trusted".

"If the head of the organisation \& management level are supportive of recordkeeping systems in a regular and direct way, the employees will be. Everything starts from the top."

"Getting visible support from top level management has been patchy, where we get the support we see major strides forward, where we don't, the work is harder."

Frustrations with limited support from management show with comments like: 
"All attempts to add specific requirements to performance assessment systems strongly resisted by managers. Generic statements about staff being required to use corporate systems as required are never enforced, and the worst offenders are often managers."

"If the leadership team don't stress the importance of record keeping procedures then staff will find themselves too busy to comply. "

And others sharing successful strategies noted "strong and proactive support from senior and middle management" and "responsible recordkeeping is visibly supported by top tier managers and directors".

The importance of training has been noted repeatedly (Barsoum, 2006; Di Biagio \&lbiricu, 2008; King, 2013; Edwards, 2007) as a factor in compliance in record keeping, and particularly in EDRMS systems. It is also seen as a way to allay fears (Johnston \& Bowen, 2005). The question of sufficient training had almost half or $46 \%$ either agreeing or strongly agreeing that staff had received sufficient training in the system; $31 \%$ remained neutral and 23\% disagreed. This correlates with the Archives New Zealand audit (Archives New Zealand, 2014 d) which found that $20 \%$ of organisations could show no organized approach to training. Formal training is not always effective and Oliver and Foscarini $(2014$, p.141) stress that training must be sustainable, and should be designed in accordance with user needs. When asked about successful strategies most respondents mentioned training and communicating as effective strategies for increasing trust, but also emphasizes the need for ongoing training and support by listing strategies that work:

"One to one inductions for all users of the recordkeeping system, including casual and contract people, by the records manager. Further assistance is available at any time that is convenient to the user."

"Engage with people who have concerns. Whether you can solve the issues quickly or not, fronting up and communicating is most often appreciated and fosters trust." 
And one used the strategy of "delivering 'tiny tips' along the way-never overloading with too much information at once." Others found training lacking with comments like:

"We do not do enough training and refresher education.... many do need refreshers on how the system works so they can gain trust."

"Most organisations I have worked in have limited resource with which to provide training and end user support".

Informal training, in the form of records champions, was a strategy some found successful.

Some authors suggest a link between confidence and training (Di Biagio \& Ibiricu, 2008), 39\% agreed that employees felt confident using their system, even though $46 \%$ felt they' $d$ received sufficient training. This indicates there are other factors affecting user confidence, and ongoing support was mentioned several times in the text answers:

"If people don't get sufficient and ongoing support they won't use it."

"I am not sure that the issue is always about trust - it is often about users having the skills and confidence to use the provided applications."

"The helpdesk is a good way to help unconfident users."

International research indicates that issues of trust can be affected by changes in systems (Nguyen et al., 2009; McLeod \& Childs, 2013; Edwards, 2007) and this research reiterated that with changes in systems found to affect trust by most (64\%), while $21 \%$ remained neutral, perhaps not having implemented a change, and 15\% disagreed, perhaps having been through successful changes. This makes the text questions potentially useful, as they could pinpoint success in changes. One respondent felt that trust was built by experience because "hardly anyone trusts a brand new system." This was repeated by another saying "people will come round if they see and then start to experience the benefits of new processes - it just takes longer for some than for others!" And another found that "If system errors, issues and implementation problems are not remedied then there is an ongoing issue which is hard to overcome." A respondent who was in the process of 
implementing a new system found that many of the staff were blaming the new system for any user error.

On the question of staff understanding the importance of efficient recordkeeping, more respondents agreed than disagreed; with $44 \%$ agreeing and $21 \%$ disagreeing. It has been recommended (McLeod, et al., 2011) that staff should be made conscious of the importance of records management and their responsibilities to keep records, as part of training. In one organisation the records manager felt that "a lot of people in the business are not good with computers and do not see records as been [being] important in fact they see records people as been [being] a pain".

The aim of the PRA is to support the Official Information Act that ensures transparency in government and local government (Archives New Zealand, 2006; Donnelly, 2008). The PRA can be compared to Jury Duty, a somewhat tedious piece of legislation that places extra and seemingly unrewarding duties on us. Just as jurors contribute to the justice process (Ministry of Justice, 2014) adequate recordkeeping contributes to something bigger than us: the transparency of government that goes into a true democracy. In studies in New Zealand; King (2013) suggested that councils need more guidance on legal responsibilities and Edwards (2007, p.65) that it is important for staff to have an understanding of their recordkeeping responsibilities. In this research, to the question about staff trusting their system to help them adhere to mandatory PRA requirements, most records managers remained neutral (51\%), three or $8 \%$ disagreed or strongly disagreed, $41 \%$ agreed and strongly agreed. The fact that fewer than half agreed with this implies that compliance with the PRA is not always important to staff, and this was confirmed in text answers where a record manager stated that: "Our management realise the importance of the EDMRS and $P R A$, but not a priority." Another said that some staff do not really care: "These people are only concerned about "now" and do not think about the future ...." Only one respondent listed talking to customer groups about the system, and their obligations under the PRA, as a successful strategy towards compliance. This implies that while adequate training in system use is taking place in most of the organisations participating in the survey, there is less emphasis on 'the why', or the reasons organisations need efficient recordkeeping that meets the standards of the PRA. 
Differences in organisations and organisational cultures showed clearly when records managers were asked how staff bypass the recordkeeping system. When it comes to information sharing: "Records managers are ... by nature of their education and training, more conscious of the advantages of sharing information ..." (Oliver \& Foscarini, 2014 p.63). This puts records managers in a position to notice non-compliance, and thirty five records managers listed the ways their systems were bypassed; while one thought that would be unethical and unlikely to be happening in their organisation. Trust is both difficult to define and to measure (Nooteboom, 2010). While most records managers felt (59\%) that their staff trust their recordkeeping systems, most (over $80 \%$ ) listed ways staff found to bypass the system, or to hoard information. This implies that while there may be degrees of trust, trust is not absolute. Most listed personal 'hoarding of information' methods; these included saving to desktops, saving to shared drives, using the cloud, using usb sticks and external hardrives as well as sending records to email. Some also alter classification structure and change metadata. Two mentioned that some staff would simply not file anything while another stated that some staff felt that their work was "far too important to file in a recordkeeping system". Additional insights included:

"A hard message to pass through for us has been that the records and information belong to the organisation, not individual staff members."

"When staff get over the "this is my stuff" idea, then the value of recordkeeping and trust in RK [recordkeeping] systems can be demonstrated really well to produce tangible results for the team."

Some organisations were preventing some of these methods by disabling drives. Strategies used to promote trust including ongoing support, demonstration of effectiveness, and training and communication. McLeod, et al. (2011) also found in their project that there was no 'one size fits all' approach and that solutions that could work in some organisations should be avoided in others. One respondent found that going back to basics was important "explaining the concepts and reasons for good record and document management.

Employees needs to know the why as well as the what to do. Context helps to cement the ideas." 
One manager recommended the use of recordkeeping champions "Having one person in each team who understands the value of good recordkeeping and who promotes good recordkeeping in the team can make a huge difference." Another called this "peer pressure' and found it effective; though peer pressure was found in another organisation to have negative effects, when new staff joined workgroups that were not trusting of the system. One was unsure that any strategy was totally effective because some staff do not really care. Several expanded on the concept of the slow building of trust by showing staff the advantages of retrieval and information sharing, but they noted that trust can be lost a lot faster than it takes to build it, and it can be difficult to regain.

Several records managers saw the same solution for problems they were experiencing in managing records. As Loadman (2001) found; the position of the recordkeeper within an organisation can impact on their effectiveness. One respondent reiterated this by saying: "The people who are entrusted with responsibility are usually placed far down the hierarchical pecking order, and, in organisational and corporate terms, are treated as such. The very way in which organisations treat their records and archives (IM) staff serves to actually undermine the stated goal of creating, managing and maintaining good information for now and for the future." McLeod et al. (2011) saw demonstrating leadership as a way forward for records professionals. Not all records managers all are in a position to assume this role. This leaves some in a position to see the problems in recordkeeping in their organisation, and to see the potential solutions but, unless they have management support, to be unable to implement them. Potential solutions suggested by records managers included making organisational recordkeeping standards mandatory:

"management have to buy in and make records keeping a part of there [their] staff reviews and training"

"There needs to be consequences when employees aren't doing the right thing. With no consequences, no one takes it seriously."

"Having record keeping as part of performance management may be a good strategy for embedding good habits"

"If your system is not mandatory for the organisation it is doomed to failure." 
And for one record manager: "All attempts to add specific requirements to performance assessment systems strongly resisted by managers." In their audit Archives New Zealand (2014d) also found that many public offices needed to ensure that recordkeeping requirements were included in their future plans.

Records managers also found success in compliance through shaping the system to user needs; Johnston and Bowen, (2005) emphasise the need for easy workflows that do not interrupt wok practices; and McLeod et al. (2011) that records management practices should be designed to not be intrusive. As records manager found:

"It has to be EASY and seamless, or they just won't do it."

"Saving needs to quick and simple to ensure everyone does it in the common system."

And several others mentioned automation, and ease of use as a strategy towards compliance.

"Automating 99\% of it so that if our staff use our systems, then records are made \& kept."

"... trust in recordkeeping systems is largely relative to the extent to which a recordkeeping system (or systems that contains records) align to business processes and how people work."

Other comments included concerns over the view that digitising everything would solve all the organisations information management issues, and an account of the difficulties experienced in using file classification.

One records manager gave an example of the loss of trust: their organisation had been left without a dedicated records manager for several years. The previous momentum, including trust in their system, was left to languish and the recordkeeping was left to 'go feral'. He stated that if people don't get ongoing support they won't use a system and "now we've got the task of rebuilding the trust, awareness and staff capability." 


\subsection{Further research opportunities.}

Factors affecting compliance in using recordkeeping systems need to be studied, in order to achieve the aim of keeping records that are complete and comprehensive. Trust in the recordkeeping system is only one of the factors affecting compliance in recordkeeping, but it is not the only one. All factors need to be examined. One factor that was raised repeatedly in text answers was convenience, or the ways in which recordkeeping is automatically integrated into workflows. There is a potential for future research into adapting recordkeeping to workflows in different organisations as a strategy for compliance.

Questions in this research were deliberately kept as broad as possible to be able to apply to all public sector organisations. This strategy meant that not all questions were relevant to every respondent, or easily answered. One respondent noted that they found the questions difficult to answer because their organisation consisted of different workgroups, with differing attitudes to recordkeeping. This implies a potential to undertake case studies in larger organisations, to understand the differing information behaviours within different workgroups or departments, and possibly between different types of organisations.

An unexpected response received to the questionnaire was an email asking why this research had been restricted to agencies affected by the PRA, as businesses were also affected by lack trust in recordkeeping systems. Further research comparing compliance and attitudes between the public and the private sector to recordkeeping systems could prove useful.

Another opportunity for further research became apparent when a respondent noted that this survey didn't allow for the way some organisations affected by the PRA work, and this was also mentioned in the Archives New Zealand (2014d) audit where they mentioned that some public offices have complex business requirements and use a number of digital business systems. Research within these complex recordkeeping environments could illuminate their different work practices. 


\section{Conclusion}

This project has investigated the levels of trust in recordkeeping systems demonstrated by staff in the public sector in New Zealand; as observed by records managers. Most records managers surveyed view their recordkeeping system as successful. The factors raised in the literature; from senior management involvement to organisational culture, do impact recordkeeping in New Zealand. Most participants in this research felt that management support and involvement is vital, and most also felt that this was in place in their organisations. Some organisations have overcome problems of trust and compliance successfully, using different strategies, while others are still struggling. Different levels of trust were also evident, demonstrated by information hoarding methods. While trust in the recordkeeping system is not the only factor affecting compliance, it is certainly an important one. People are less likely to trust a system that they do not see their managers using, that is not set up properly, is not integrated into their workflow, is not easy to use, and that lets them down too often. Without trust we will continue to see staff finding ways to bypass the system, resulting in incomplete recordkeeping. It is vital for records managers to build trust; this is a slow process, and trust, once lost, is difficult to regain. 


\section{Acknowledgements}

With thanks to my supervisor, Gillian Oliver, for her help and support; and also to all the recordkeepers who participated in this research. I'm also grateful to my friends and family for their patience, and cooking. A special thanks to my 'virtual classmate' Catherine, for her support via email. 


\section{Bibliography}

Archives New Zealand. (2006). Fact Sheet: "Make a Record".

Accessed June 1, 2011 from

http://archives.govt.nz/f1-make-record

Archives New Zealand (2014a). Archives New Zealand Standards Policy.

Retrieved May 19, 2014 from

http://archives.govt.nz/ArchivesNewZealandStandardsPolicy

Archives New Zealand (2014b). F16: Public Records Act and Local Government.

Retrieved February 4, 2014 from

http://archives.govt.nz/f16-public-records-act-2005-pra-and-local-government

Archives New Zealand (2014c). ISO 15489: International Standard on Records

Management.

Retrieved February 4,2014 from

http://archives.govt.nz/advice/international-standards/iso-15489-internationalstandard-records-management

Archives New Zealand (2014d). State of Government Recordkeeping and Public Records Act 2005 audits 2011/12 (G.61A).

Retrieved May 19, 2014 from

http://www.parliament.nz/ennz/pb/presented/papers/50DBHOH PAP26165 1/arch ives-new-zealand-te-rua-mahara-o-te-k\%C4\%81wanatanga-state

Barsoum, M. (2006). Records management mistakes to avoid. AlIM E - Doc Magazine, 20(3), 30-33. Retrieved from http://search.proquest.com/docview/216570465?accountid=14782

Bearman, D. (1995). Archival strategies. American Archivist, 58 (4), 380-413. 
Retrieved from http://www.jstor.org/stable/40293938

Carlisle, D. K. (2008). Records management standards: What they are and why they are important. In B. W. Dearstyne (Ed.), Leading and managing archives and records programs: Strategies for success (pp. 45-67). London: Facet

Chawla, A., \& Kelloway, E. K. (2004). Predicting openness and commitment to change. Leadership \& Organization Development Journal, 25(5), 485-498. Retrieved from http://search.proquest.com/docview/226919029?accountid=14782

Cox, R. J. (2006). Ethics, accountability, and recordkeeping in a dangerous world. London: Facet.

Di Biagio, M. L., \& Ibiricu, B. (2008) "A balancing act: learning lessons and adapting approaches whilst rolling out an EDRMS", Records Management Journal, Vol. 18 Iss: 3, pp.170 - 179 . Retrieved from Proquest.

Donnell, L. (2008). Archives and ombudsmen - natural allies. Office of the Ombudsman. Retrieved 1/05/2014 from http://www.ombudsman.parliament.nz/newsroom/item/archives-and-ombudsmen$\underline{\text { natural-allies }}$

Downing, L. (2006). 'Implementing EDMS: Putting people first', Information Management Journal, vol. 40, no. 4, pp. 44-50. Retrieved from http://www.arma.org/bookstore/files/downing.pdf

Edwards, A. E. (2007). Electronic document \& records management system implementation: Best practice change management: Submitted to the school of information management, Victoria university of Wellington in partial fulfilment of the requirements for the degree of master of library and information studies. 
Farazmand, A. (2014). Crisis and emergency management: Theory and practice. Boca Raton, FL: CRC Press.

Farley, T., Broady-Preston J., \& Hayward, T. (1998). Academic libraries, people and change: A case study of the 1990s. Library Management, 19(4), 238-251. Retrieved from http://search.proquest.com/docview/198867807?accountid=14782

Foscarini, F. (2010). Understanding the context of records creation and use: 'Hard' versus 'soft' approaches to records management. Archives \& Museum Informatics, 10(4), 389-407.

Gunnlaugsdottir, J. (2009). The human side of ERMS: An Icelandic study. Records Management Journal, 19(1), 54-54. doi:10.1108/09565690910937245 Retrieved 18.09.213 from Proquest.

Hofstede, G. (2011). Dimensionalizing Cultures: The Hofstede Model in Context. Online Readings in Psychology and Culture, 2(1). Retrieved from http://dx.doi.org/10.9707/2307-0919.1014

Huotari, M., \& livonen, M. (2004). Trust in knowledge management and systems in organizations. Hershey, PA: Idea Group Publishing.

Johnston, G.P., \& Bowen, D.V. (2005). "The benefits of electronic records management systems: a general review of published and some unpublished cases", Records Management Journal, Vol. 15 Iss: 3, pp.131 - 140.

Retrieved from Proquest

Joseph, P., Debowski, S., \& Goldschmidt, P. (2012). Paradigm shifts in recordkeeping responsibilities: Implications for ISO 15489's implementation. Records Management Journal, 22(1), 57-75. 
Retrieved from doi: http://dx.doi.org/10.1108/09565691211222108

Judge, W., \& Thomas, D. (2009). Organizational change capacity: The systematic development of a scale. Journal of Organizational Change Management, 22(6), 635649. Retrieved doi: http://dx.doi.org/10.1108/09534810910997041

Kegan, R., \& Lahey, L. L. (2001). The real reason people won't change. Harvard Business Review, 79 (10), 85-92.

Kennedy, J., \& Schauder, C. (1998). The records life cycle model and the records continuum model. In Records management: A guide to corporate recordkeeping (2nd ed., pp. 912). Melbourne: Addison Wesley Longman

King, V. (2013). Recordkeeping in council-controlled organisations: An investigation into local body involvement and the implementation of formal recordkeeping programmes. Submitted to the School of Information Management, Victoria University of Wellington in partial fulfillment of the requirements for the degree of master of library and information studies.

Leedy, P. D., \& Ormrod, J. E. (2013). Practical research: Planning and design. U.S.A. :Pearson.

Loadman, J. (2001). Does the position of records management within the organisation influence the records management provision? Records Management Journal. Vol 11lss:1, pp.45-63.

Retrieved from Proquest.

McDonald, J. (2005). The wild frontier ten years on. In Julie McLeod \& Catherine Hare (Eds.), Managing Electronic Records (pp. 1-17). London: Facet.

MacDonald, R. (2012). "Trust." Software World May 2012: 19+. General OneFile. Web. 21 Jan. 2014. Retrieved from

http://go.galegroup.com.helicon.vuw.ac.nz/ps/i.do?id=GALE\%7CA293559117\&v=2.1 $\underline{\text { \&u}=v u w \& i t=r \& p=\mid T O F \& s w=w \& a s i d=1 c 410 a d d c b b b a 981 \mathrm{dda} 5 \mathrm{ffcd} 0463 \mathrm{dd} 46}$ 
McKemmish, S. (2005). Traces: document, archive, archives In McKemmish, S., Piggott, M., Reed, B. \& Upward, F. (Eds.) Archives: Recordkeeping in society. Wagga Wagga: Centre for Information Studies

McLeod, J., Childs, S., \& Hardiman, R. (2011). Accelerating positive change in electronic records management: headline findings from a major research project. Archives and Manuscripts, 39 (2). pp. 66-94. ISSN 0157-6895 Retrieved from: http://nrl.northumbria.ac.uk/5604/1/McleodChildsHardiman2011ArchivesManuscri pts.pdf

McLeod, J., \& Childs, S. (2013). A strategic approach to making sense of the "wicked" problem of ERM . Records Management Journal (0956-5698), 2013, Volume 23, Issue 2, pp. $104-135$. Retrieved from Proquest

McNeish, J., \& Mann, I. J. S. (2010). Knowledge sharing and trust in organizations. IUP Journal of Knowledge Management,8(1), 18-38. Retrieved from http://search.proquest.com/docview/199363016?accountid=14782

Ministry of Justice (2014). Jury Service Retrieved April 25, 2014 from http://www.justice.govt.nz/services/access-to-justice/jury-service-1

Nguyen, L. T., Swatman, P. M.C., Fraunholz, B., \& Salzman, S. (2009). EDRMS implementation in the Australian public sector, in ACIS 2009 : Evolving Boundaries and New Frontiers: Defining the IS Discipline : Proceedings of the 20th Australasian Conference on Information Systems, ACIS, Melbourne, Vic., pp. 915-928.

Retrieved 02.01.2014 from http://dro.deakin.edu.au/view/DU:30024943

Nielsen. (2010). Government Recordkeeping Survey Report 2010 - Public 
Offices. Retrieved 03.04.2014 from

http://archives.govt.nz/full-report-2010-government-recordkeeping-survey-publicoffices

Nooteboom, B. (2010). The dynamics of trust: Communication, action and third parties. Comparative Sociology, 10(2), 166-185. Doi: 10.1163/156913311X566553

Nothdurft, F., Heinroth, T., \& Minker, W. (2013). The Impact of Explanation Dialogues on Human-Computer Trust. In M. Kurosu (Ed.), Human-Computer Interaction. Users and Contexts of Use (Vol. 8006, pp. 59-67): Springer Berlin Heidelberg.

Oliver, G. (2011). Organisational culture for information managers. Witney: Chandos Publishing (Oxford) Ltd. Retrieved 11/10/2013 from http://www.chandospublishingonline.com.helicon.vuw.ac.nz/content/h54l16/?genr e=book\&isbn=978-1-84334-650-0

Oliver, G., \& Foscarini, F. (2014). Records management and information culture: Tackling the people problem. London: Facet Publishing.

Qualtrics. (2013). Research Suite.

Retrieved 11.10.2014 from

http://qualtrics.com/research-suite/\#enterprise

Reed, B. (2005). Records. In Sue McKemmish, Michael Piggott, Barbara Reed \& Frank Upward (Eds.), Archives: Recordkeeping in Society (pp. 101-130). Wagga Wagga: Centre for Information Studies.

Reed, B. (2009). Project 9 report: Preservation of Web 2.0 content. NSW: Recordkeeping Innovation. Retrieved 11/05/2014 from http://gov2.net.au/files/2009/12/Project-9-Final-Report.doc\# Toc248025982 
Shepherd, E., Stevenson, A., \& Flinn, A. (2009). The impact of freedom of information on records management and record use in local government: A literature review. Journal of the Society of Archivists, 30(2), 227-248.

Shepherd, E., \& Yeo, G. (2003). Managing Records: A Handbook of Principles and Practice. Facet Publishing, London and Neil Schuman publishers, Inc., New York

Smith, I. (2005). Continuing professional development and workplace learning 13:

Resistance to change - recognition and response. Library Management, 26(8), 519-

522. Retrieved 12.12.2013 from

http://search.proquest.com/docview/198858031?accountid=14782

Sun, S. (2008) Organizational Culture and Its Themes. International Journal of Business and Management. Retrieved 12.12.2013 from

http://www.ccsenet.org/journal/index.php/ijbm/article/view/760

Sundqvist, A. (2011). Documentation practices and recordkeeping: A matter of trust or distrust? Archival Science, 11(3-4), 277-291. doi:http://dx.doi.org/10.1007/s10502-011-9160-3

Thurston, A. (2012). Trustworthy Records and Open Data. The Journal of Community Informatics, 8(2). Retrieved 21.01. 2014 from http://ci-journal.net/index.php/ciej/article/view/951

Oxford University Press. (2014). Oxford Dictionary "trust". Retrieved January 22, 2014 from http://www.oxforddictionaries.com/definition/english/trust

Williamson, V. (2008). Relationships and engagement: The challenges and opportunities for effective leadership and change management in a Canadian research library. Library Management, 29(1/2), $29-40$ 
300266555

Wilson, M. $(2005,07)$. The psychology of motivation and employee retention. Maintenance Supplies, 50, 48-49.

Retrieved from Proquest. 


\section{Tables and Figures}

Table 1, Qualtrics

Table 2 Qualtrics

Table 3 Qualtrics

Table 4 Qualtrics

Table 5 Qualtrics

Table 6 Qualtrics

Table 7 Qualtrics

Table 8 Qualtrics

Table 9 Qualtrics

Table 10 Qualtrics

Table 11 Qualtrics

Table 12 Qualtrics

Figure 1 The Continuum Model from Frank Upward's 'Modelling the continuum as

paradigm' (Upward, 2000, p.123)

Figure 2 Qualtrics

Figure 3 Qualtrics

Figure 4 Qualtrics

Figure 5 Qualtrics

Figure 6 Qualtrics

Figure 7 Qualtrics

Figure 8 Qualtrics

Figure 9 Qualtrics

Figure 10 Qualtrics

Figure 11 Qualtrics

Figure 12 Qualtrics

Figure 13 Qualtrics

Figure 14 Excel

Figure 15 Excel 
Appendix A - questionnaire

Q1 I feel that our current recordkeeping system is successful.

Strongly disagree Disagree Neutral Agree Strongly Agree Don't know

Q2 Our current recordkeeping system is trusted by employees.

Strongly disagree Disagree Neutral Agree Strongly Agree Don't know

Q3 Lack of trust in our recordkeeping system impacts on employee use of the system.

Strongly disagree Disagree Neutral Agree Strongly Agree Don't know

Q4 Our employees have received sufficient training in our recordkeeping system.

Strongly disagree Disagree Neutral Agree Strongly Agree Don't know

Q5 Our employees feel confident using our recordkeeping system.

Strongly disagree Disagree Neutral Agree Strongly Agree Don't know

Q6 Employees at our organisation understand the importance of efficient recordkeeping. Strongly disagree Disagree Neutral Agree Strongly Agree Don't know

Q7 My manager understands and trusts our recordkeeping system.

Strongly disagree Disagree Neutral Agree Strongly Agree Don't know

Q8 My manager actively promotes the use of our recordkeeping system.

Strongly disagree Disagree Neutral Agree Strongly Agree Don't know 
Q9 In my organisation management attitudes affect employee compliance in recordkeeping.

Strongly disagree Disagree Neutral Agree Strongly Agree Don't know

Q10 Changes in recordkeeping systems affect employee trust in the systems.

Strongly disagree Disagree Neutral Agree Strongly Agree Don't know

Q11 Employees are confident that our recordkeeping system helps them to comply with the aims of the Public Records Act.

Strongly disagree Disagree Neutral Agree Strongly Agree Don't know

Q12 Employees are confident that they would be able to retrieve information added to our recordkeeping system in five years' time.

Strongly disagree Disagree Neutral Agree Strongly Agree Don't know

Q13 Please share the most effective strategy you have found to promote trust in your organisations recordkeeping system.

Q14 Please share some of the ways employees in your organisation have found to bypass the system.

Q15 Do you have any other comments relating to employee trust in recordkeeping systems? 


\section{Appenix B - questionnaire cover}

\section{Trust in Recordkeeping - A Survey}

My name is Jean Hitchcock and I am student 580 MIS Victoria University of Wellington (VUW). The aim of this research is to investigate the to what extent records managers perceive that levels of trust impact on employee use of organisational recordkeeping systems. I'd also like to find out what strategies records managers implement to encourage employee use of recordkeeping systems. The survey has been restricted to those organisations affected by the Public Records Act (PRA).

It is hoped this will provide insight into the some of the common problems experienced by records managers, and that suggestions will be found that will make compliance with the PRA more achievable.

All records managers of agencies affected by the Public Records Act are invited to participate in this survey. The questions are relevant for both paper and electronic recordkeeping. It will take only approximately 10 minutes to complete. The first eleven questions are multiple choice, and the last two (text) are optional. The School of Information Management's Human Ethics Committee has given this research ethical approval. The survey is anonymous; no information that identifies you individually will be collected. Throughout the project the data will be stored securely and accessible only to me. All survey responses will be destroyed two years after the conclusion of the study.

If you would like to receive a summary of findings, email me at hitchcjean@myvuw.ac.nz. Similarly, if you have any questions about your rights as a participant or to discuss any aspect of this study, please get in touch by phone 068771087 or e-mail hitchcjean@myvuw.ac.nz.

If you have read the information above and agree to participate in the study please click on the link below or copy and paste into a web browser. 
300266555

11340 words

Jean Hitchcock

excluding bibliography and appendices 
300266555 